\title{
LOS VÍNCULOS ENTRE LA SAL Y EL DIOS HÉRCULES en Roma, Ostia y Alba FuCENS \\ The links Between salt and the god Hercules in Rome, Ostia and Alba Fucens
}

David Serrano Ordozgoiti

Universidad Complutense de Madrid

DASERRAN@UCM.ES

\section{RESUMEN}

A menudo, el interés científico por la sal ha encontrado provechosos socios en los investigadores de la economía romana, más que en su relación simbólica con los pobladores. Por ello, el estudio se propone analizar la relación existente entre la sal y la religión romana, tomando para ello el ejemplo del culto de Hércules en Roma, Ostia y el centro de Italia. Con ese fin se analizará en un primer momento la figura del dios itálico en su contexto originario, subrayando sus diferencias conceptuales con el dios grecorromano más tardío y su relación con la sal y su culto urbano. En un se-

\section{Abstract}

The scientific interest in salt has often found useful partners in researchers of the Roman economy, rather than in its symbolic relationship with the settlers. For this reason, the study aims to analyse the relationship between salt and Roman religion, taking the example of the cult of Hercules in Rome, Ostia and central Italy. To this end, the figure of the Italic god in its original context will be analysed first, highlighting its conceptual differences with the later Greco-Roman god and its relationship with salt and its urban cult. In a second moment, the role that the god plays with 
gundo momento, se revisará el papel que desempeña el dios con la ciudad de Ostia y su casuística, para, en último lugar, estudiar la devoción de la divinidad en el centro de Italia, tremendamente radicada desde tiempos muy remotos en santuarios como el de Alba Fucens. the city of Ostia and its casuistry will be reviewed, in order to, finally, study the devotion of the divinity in the centre of Italy, tremendously rooted since very remote times in sanctuaries such as that of Alba Fucens.

\section{Palabras Clave}

Sal, religión romana, Hércules, Roma, Ostia, Alba Fucens, Via Salaria
KeYWORDS

Salt, Roman Religion, Hercules, Rome, Ostia, Alba Fucens, Via Salaria

Fecha de recepción: 15/03/2018

Fecha de aceptación: 18/11/2018 


\section{INTRODUCCIÓN}

El estudio de la sal, de reciente interés en la historiografía antigua, ha privilegiado desde siempre un enfoque económico de la realidad. Este curioso y esencial material, común en nuestros hogares, ha provocado siempre en la mente de los autores modernos un deseo económico. Lo demuestran el gran número de monografías dedicadas al cloruro sódico en el Imperio Romano: su producción en las salinas dispersas por todo el Mediterráneo, su comercio y distribución, su aplicación en salazones, siempre muy bien identificadas y excavadas en todo el litoral Mediterráneo, como por ejemplo el célebre caso de Baelo Claudia, hoy Bolonia, en el litoral gaditano. ${ }^{1}$ Pero hasta ahora muy poca atención se ha prestado a la forma en que los antiguos percibían este material, con toda seguridad como un bien que comerciar, pero seguro también como algo más. La visión de los antiguos era mucho más religiosa que la que solemos tener nosotros y es por ello que el estudio de la relación existente entre la sal y la reli-

1. Para el caso hispano cfr., entre otros, Mangas Manjarrés y Hernando Sobrino, 1991, pp. 219-332; Mangas Manjarrés y Hernando Sobrino, 2011, pp. 11-82 y también las aportaciones de diversos autores recogidas en Frías Castillejo et al., 2005, pp. 27-292. Para el caso italiano cf. recientemente Russo y Goffredo, 2018. Para el caso griego y del oriente romano cf. Carusi, 2007, pp. 221-233; 2009; 2011, pp. 149-154. 
gión en Roma se hace de vital importancia para comprender mejor la forma de actuar de los antiguos en un mundo tan alejado y al mismo tiempo cercano al nuestro.

En este ensayo se plantea al lector la relación existente en el centro de Italia entre la sal y el dios Hércules, famoso héroe divinizado en el mundo griego. ${ }^{2} \mathrm{El}$ objetivo fundamental aquí es el de indagar hasta donde sea posible la antigua relación entre el material y las manifestaciones religiosas ligadas al dios en Roma, lo que no es fácil en muchos casos debido a la fragmentariedad y a la antigüedad de un culto tan drásticamente trasformado a través de los siglos. Para llevar a cabo el estudio, por tanto, se tomarán en consideración tanto fuentes literarias, cuando sea posible, como fuentes arqueológicas, más abundantes pero que requieren un cuidadoso estudio y en muchos casos no nos ofrecen un cuadro suficientemente completo para fundamentar de forma completa los discursos. El estudio se dividirá en tres secciones, correspondientes a zonas geográficas diferentes pero interconectadas entre sí: por un lado, Roma y el Foro Boario, por el otro la Vía Salaria y la colonia de Ostia, y finalmente el resto de Italia central, con especial atención en el enclave de Alba Fucens.

\section{Roma y el Ara Maxima Herculis}

La tradición literaria clásica, analística y anticuaria, es unánime en atribuir a la zona de Roma situada entre el Tíber, el Capitolio y el Aventino, conocida con el nombre de Forum Boarium o Bovarium, ${ }^{3}$ una antigüedad superior al del resto de zonas habitadas desde tiempo inmemorial. ${ }^{4}$ Desde finales del Bronce, esta zona se convirtió en un importante punto comercial o emporio debido a que suponía el lugar de encuentro fundamental de diversas vías comerciales, como el mismo río Tíber, a través de un primitivo portus, ${ }^{5}$ la vía Salaria y su prolongación transtiberina de la vía Campana, la vía Latina desde el Sur o las vías Aurelia y Triumphalis desde Etruria, entramado viario potenciado también por el fácil vado de la Isla Tiberina o la construcción del antiquísimo Pons Sublicius. ${ }^{6}$ Las pequeñas comunidades de

2. Para los estudios relativos al dios en Hispania cf. en particular Plácido Suárez, 1993, pp. 63-80; 2005, pp. 57-63; 2013, pp. 525-541.

3. Ov., Fast. VI 477-478; Varro, L.L. V 146; Paul., Fest. 27 L; Livy., XXVIII 37, 5; Prop., IV 9, 1-6.

4. Cf. Tac., Ann. XII 24, 2. Recientemente cf. Zevi, 2014, pp. 191-207.

5. Cf. Coarelli, 1988, pp. 113-127; s.v. 'Portus Tiberinus', LTUR 4, pp. 155-156; SR 1, pp. 143-151.

6. Que la tradición atribuye al rey Anco Marcio. Cf. Livy., I 33, 6; Dion. Hal., Ant. III 45, 2; Plut., Vit. Num. 9. De antigua denominación volsca, en este puente se desarrollaban innumerables y antiquísimas festividades y ritos aún hoy difíciles de explicar (s.v. 'Pons Sublicius', LTUR 4, pp. 112-113). Cf. Paul., Fest. 14, 450-452, 474 L; Varro, L.L. V 83, 7, 44; Dion. Hal., Ant. I 38, 2-3; III 45, 2; Ov., Fast. V 621-622; Macrob., Sat. I 11, 47. 
pastores-agricultores de las colinas circundantes intercambiaban sus excedentes en este lugar y es por ello que la zona se convirtió paulatinamente en un punto necesario de encuentro y también de cultos y sacrificios. Así es como surgen cultos antiquísimos como los de Fortuna y Mater Matuta, Portunus, Ceres, Libero y Libe$\mathrm{ra}^{7}$ y, el más destacable de todos, el culto de Hércules en el Ara Maxima Herculis, reproducido más tarde con matices diversos en multitud de estructuras y edificios cultuales, algunos aún existentes, como el Aedes Aemiliana Herculis, el Aedes Herculis Victoris ad portam Trigeminam o el Aedes Herculis Pompeiani. ${ }^{8}$ En esta misma zona, probablemente en un área comprendida entre la ladera septentrional del Aventino, el Tíber y el clivus Publicius, surgía, según los testimonios clásicos, ${ }^{9}$ un espacio denominado Salinae, ${ }^{10}$ que muy posiblemente debía su nombre a la presencia de almacenes de sal proveniente de las salinas de la desembocadura del Tíber, y que confirma la firme correlación existente ya desde época protohistórica entre el comercio de sal, el ganado y el culto empórico de Hércules. El propio Solino es explícito al ligar la fortuna mitológica de este preciso espacio al mito de Caco y Hércules: Qui Cacus habitavit locum, cui Salinae nomen est: ubi Trigemina nunc porta. ${ }^{11}$

7. Para más detalles sobre estos cultos cf. ARA, 423-426; Castagnoli, 1979, pp. 145-152; Coarelli, 1988, pp. 113-126, 205-437; Le Bonniec, 1958, pp. 266-277; s.v. 'Ceres, Liber, Liberaque, aedes; aedes Cereris', LTUR 1, 260-261; s.v. 'Fortuna et Mater Matuta, aedes', LTUR 2, 281-285; s.v. 'Portunus, aedes', LTUR 4, 153-154; Palmer, 1990, pp. 234-237; Richardson, 1992, pp. 80-81, 155, 246, 320; Ruggiero, 1987, pp. 1622; Ruggiero, 1991-1992, pp. 253-286; Sordi, 1984b, pp. 127-139; Torelli, 1993, pp. 93-97.

8. De estos santuarios no hablaremos por tratarse de complejos más tardíos, de época medio y tardo republicana. Para más detalles cf. ARA, 429-432; Coarelli, 1988, pp. 77-106, 147-204; s.v. 'Hercules, aedes Aemiliana', LTUR 3, 11-12; s.v. 'Hercules Invictus, aedes (forum Boarium)', LTUR 3, 15; s.v. 'Hercules Pompeianus, aedes', LTUR 3, 20-21; s.v. 'Hercules Victor, aedes (ad portam Trigeminam)', LTUR 3, 2223; Lyngby, 1954, pp. 7-19, 24-29; Martin, 1987, pp. 90-98; Palmer, 1990, pp. 234-240; Richardson, 1992, pp. 187-189; Ziolkowski, 1988, pp. 309-333; Ziolkowski, 1992, pp. 46-50.

9. Solin., I 8; Frontin., Aq. V 9; Livy., XXIV 47, 15; Paul., Fest. 272 L; Plaut., Capt. 90.

10. Su existencia está confirmada al menos desde el año 312 a.C., cuando el lugar fue elegido como punto terminal del aqua Appia por parte del censor Apio Claudio, quien también sería el encargado de publicitar y reformar el culto de la cercana Ara Máxima. Una cierta continuidad en el uso del espacio se podía observar hasta 1888, cuando fue demolida la antigua Salara Vecchia, el almacén oficial de sal a los pies del propio Aventino (Coarelli, 1988, p. 111; s.v. 'Hercules Invictus, ara Maxima', LTUR 3, 16; s.v. 'Salinae', LTUR 4, 229).

11. Solin., I 8. ARA, 423-425; Levi, 1997, pp. 25-32; Coarelli, 1988, pp. 107-113; Ferenczy, 1976; s.v. 'Hercules Invictus, ara Maxima', LTUR 3, 15-17; s.v. 'Salinae', LTUR 4, 229; Marcos Casquero, 2002, pp. 65-67; Palmer, 1965, pp. 293-324; Richardson, 1992, pp. 162-164, 341; SR 1, 127, 131-135; Torelli, 1993, pp. 106-107; 2006, pp. 577-579; Van Berchem, 1967, pp. 307-338. Cf. también recientemente Battaglini, 2016, pp. 51-64. 
El culto del Hércules del Ara Máxima experimenta, desde su conformación originaria en la protohistoria, una reformulación extraordinaria hasta su definitiva configuración e interpretatio graeca a finales del siglo III a.C., cuando Diana y Hércules son sustituidos definitivamente por los dioses olímpicos del panteón griego. Como si de una estratigrafía se tratase, los diferentes "estratos" de Hércules se van superponiendo los unos a los otros desde el principio, partiendo primero de una fase itálica originaria del Bronce para luego irse aculturando a causa de influencias fenicias primero, entre los siglos XI y IX a.C., y posteriormente griegas, a partir del siglo VII a.C. ${ }^{12}$ El Hércules más antiguo, presente desde los inicios en Italia, en el Lacio y particularmente en el área Sabina, es la divinidad suprema del panteón itálico. Así lo demuestran, por ejemplo, los frecuentes epítetos de invictus, victor o custos. Lejos de ser el héroe griego de los athla, el Hércules itálico es el dios protector de las actividades pastoriles, de los rebaños, de la trashumancia, del comercio, de sus comerciantes y de las aguas termales. Se conforma así una divinidad cercana a las actividades agro pastoriles básicas de las comunidades protohistóricas itálicas, protegiendo por igual a personas, animales y bienes de los accidentes y las fuerzas hostiles. Fundamentalmente anicónico en sus orígenes, es tan sólo más tarde, gracias al contacto con las ricas tradiciones figurativas del Mediterráneo oriental, cuando adquiere una imagen más reconocible y cercana al Herakles de tradición griega. Es así como, en un segundo momento, el Hércules itálico adquiere características cercanas al Melqart fenicio, ${ }^{13}$ muy conocido también en otras zonas del Mediterráneo. ${ }^{14}$ Por último, la intensa influencia y prestigio del comercio griego en la zona, acaban por transformar el culto del Hércules de Foro Boario, dotándole de nuevos caracteres helénicos, como la práctica del sacrificio graeco more, es decir, con la cabeza descubierta y coronada de laurel, la presencia de la oferta de la décima o la ya mencionada iconografía, que acaba por imponerse por todo el Lacio y es de la que conservamos los vestigios más significativos. ${ }^{15}$

A través del filtro mitológico y literario es como mejor se perciben estos cambios en la figura del Hércules del Ara Máxima. Uno de los núcleos mito-históricos

12. Contra Marcos Casquero, 2002, pp. 104-105, que piensa que el Hércules del Ara Máxima es en realidad una divinidad foránea greco-oriental con aportaciones etruscas e itálicas.

13. Además de las ya recogidas por D. van Berchem (1967), Torelli añade dos características más para el Hércules-Melqart de influencia chipriota en su análisis arqueológico, una de carácter iconográfico y otra de carácter cultual (Torelli, 1993, pp. 108-110; 2006, pp. 582-583).

14. Como, por ejemplo, en la conocida colonia fenicia de Gádir (Cádiz).

15. Levi, 1997, pp. 43-58; Coarelli, 1988, pp. 127-129; Marcos Casquero, 2002, pp. 99-105; SR 1, 128 131; Torelli, 1993, pp. 108-110; 2006, pp. 581-583. 
más célebres es el relativo a Hércules y Caco. ${ }^{16}$ Según la leyenda, en el año 1235 a.C. habría arribado al Foro Boario Hércules tras su periplo por la isla Erythia, "situada entre las brumas de Occidente", ${ }^{17}$ llevándose consigo los bueyes del gigante Gerión. Caco/Fauno, hijo de Vulcano y mítico rey de los Sículos, inquilino del Aventino/ Palatino que, como vimos, habitaba en la zona de las Salinae, ${ }^{18}$ habría robado el ganado mientras este pastaba por el Foro Boario y lo habría escondido en su cueva. Pero Hércules, dándose cuenta, lo habría asesinado y Evandro, ${ }^{19}$ los compañeros del dios, ${ }^{20}$ el propio Hércules ${ }^{21}$ o un tal Garanus o Recaranus, ${ }^{22}$ según la versión, habrían fundado el culto del Ara Maxima Herculis en gratitud por su hazaña. El episodio ejemplifica perfectamente la fusión entre los elementos helenizantes, como el mito de Hércules y Gerión o el de Evandro, con los elementos etrusco-latinos, como los personajes de Caco o Fauno o la propia naturaleza del episodio, ligada a las funciones agro-pastoriles del dios antes mencionadas. ${ }^{23}$

La leyenda de Hércules y Acca Larentia es otro de los mitos relativos al dios del Ara Máxima en el que podemos entrever, además de su carácter empórico, más detalles que explican mejor la organización y la liturgia de su culto. El personaje de Acca Larentia se relaciona, en las fases más arcaicas de su culto, con los cultos infernales del Palatino noroccidental y con el Lupercal del Palatino suroccidental. ${ }^{24}$ En un mito más tardío, sin embargo, aparece vinculada a Hércules como un nobilissimum scortum. ${ }^{25}$ Cuando el aedituus del Ara Maxima Herculis pierde una apuesta, consistente

16. Para la crítica moderna cf. Marcos Casquero 2002, pp. 69-72 y Coarelli, 1988, pp. 130-139.

17. Verg., Aen. VIII 184-304.

18. Solin., I 8. Vid. supra.

19. Dion. Hal., Ant. I 39; XL 1, 6; Strabo, V 3, 3; Tac., Ann. XV 41; Macrob., Sat. III 11, 7; 12, 1; Plin., HN XXXIV 7, 33; Solin., I 7; Ps. Aur. Vict., Orig. VI 5.

20. Macrob., Sat. III 6, 12.

21. Livy., XXXIV 18-19; Ov., Fast. I 58.1-2; Prop., IV 9, 67-68; Solin., I 10; Verg., Aen. VIII 271-272.

22. Ps. Aur. Vict., Orig. VI 1; Serv., Aen. VIII 230.

23. ARA, 423-424; Coarelli, 1988, pp. 130-139; Ferenczy, 1976; s.v. 'Hercules Invictus, ara Maxima', LTUR 3, 15-17; Marcos Casquero, 2002, pp. 69-72; Moinier y Weller, 2015, pp. 272-274; Palmer, 1965, pp. 293-324; Richardson, 1992, p. 186; SR 1, 128-131; Torelli, 2006, p. 583; Van Berchem, 1967, pp. 307338. Cf. también recientemente Battaglini, 2016, pp. 51-64.

24. Varro, L.L. VI 24; Plut., Rom. V 4; Macrob., Sat. I 10, 15; Cic., Brut. I 15, 8. El sepulcro de Acca Larentia se encontraba, verosímilmente, en las laderas noroccidentales del Palatino, entre el Foro Romano y el Velabro, en el arranque de la futura Nova Via, en estrecha relación con los cultos infernales de Aius Locutius, Volupia-Angerona y Larunda-Mater Larum. El 23 de diciembre el flamen Quirinalis, encargado de los cultos funerarios y ctonios, celebraba en este lugar los Larentalia. Cf. s.v. 'Acca Larentia', LTUR 1, 13-14; SR 1, p. 130; Torelli, 1993, pp. 94-96; 2006, p. 583.

25. Macrob., Sat. I 10, 13. 
en una cena y en una noche con la prostituta Acca Larentia, jugando a los dados con el mismo Hércules, la meretriz obtiene, en pago por sus servicios, la posibilidad de contraer matrimonio con el primer hombre que encuentre al salir del santuario. El personaje en cuestión, Tarutius, es un rico etrusco, que lega finalmente todas sus posesiones a Acca y esta hace lo propio con el pueblo de Roma. En gratitud por su regalo, el pueblo romano funda un culto público en su tumba. ${ }^{26}$ El episodio pone de manifiesto las características del culto: la partida de dados hace referencia a un rito adivinatorio muy extendido en ámbito oriental y entre los etruscos; la cena reproduce una de las características iconográficas y cultuales del Hércules itálico, asimilado a la plástica griega: el Hércules $\dot{\pi} \pi \iota \tau \rho \alpha \pi \dot{\varepsilon} \zeta \iota \varsigma$ o “en el banquete”, de gran relevancia y que veremos más adelante; la unión del dios con la prostituta simboliza la hierogamia divina y la prostitución sagrada de origen oriental; y así sucesivamente. Todo ello en un ambiente de claro sabor empórico, dada la presencia del etrusco Tarutius o de la transmisión de los bienes al pueblo romano, que nos devuelve al emporio del Foro Boario en pleno siglo VI a.C. ${ }^{27}$

La ceremonia principal en honor al Hércules del Ara Máxima se llevaba a cabo cada 12 de agosto, dies natalis del santuario del Foro Boario. ${ }^{28}$ En este caluroso día, el pretor urbano realizaba, en primer lugar, una libación de vino utilizando para ello el scyphus, ${ }^{29}$ el ingens ligneus poculus, como lo llama Servio, ${ }^{30}$ la vetusta broca de culto conservada en el santuario junto a la maza del dios. ${ }^{31}$ Este objeto se conocía en ámbito griego directamente como skyphos de Herakles, ${ }^{32}$ y podía estar hecho de varios materiales, entre ellos la madera de haya. ${ }^{33}$ Tan importante era el scyphus en el culto de Hércules que se utilizaba directamente como ofrenda votiva ${ }^{34}$ e incluso se encuentra representado, junto al resto de atributos de la divinidad, en una base circular del

26. Macrob., Sat. I 10, 15-17; Lactant., Div. inst. I 20, 4.

27. Coarelli, 1988, 129-130; s.v. 'Acca Larentia', LTUR 1, 13-14; Marcos Casquero, 2002, pp. 86-91; Moinier y Weller, 2015, p. 274; SR 1, 130-131; Torelli, 1993, pp. 94-96, 105-106; 2006, pp. 583-584.

28. CIL IX, $2319=$ CIL IX, $2320=$ CIL I, p. $217=$ InscrIt XIII-2, $24=$ EDCS 35100429 y CIL IX, 4192 (p 698) = InscrIt XIII-2, $25=$ ZPE 153-266 = EDCS 55800157. Un nutrido grupo de inscripciones (CIL VI, 312-319) de avanzada edad imperial, encontradas cerca de Santa María in Cosmedin, es decir, muy cerca del Ara Máxima, recordaban estas festividades (s.v. 'Hercules Invictus, ara Maxima', LTUR 3, 16).

29. Serv., Aen. VIII 278: scypho praetor in anno semel vino libabat.

30. Serv., Aen. VIII 278. Cf. también Macrob., Sat. V 21, 11: scyphus Heraclis poculum est.

31. Solin., I 10-11; Serv., Aen. VIII 278.

32. Ath., XI 782 B; Plut., Vit. Alex. 75.

33. DA 4, 1159-1160.

34. Herculi / scyphos / votum posuit / C(aius) Clodius / C(ai) lib(ertus) Laetus / Augustalis. CIL V, 6952 $=$ ILS $3429=$ EDCS $5400203=$ EDR 108721. 


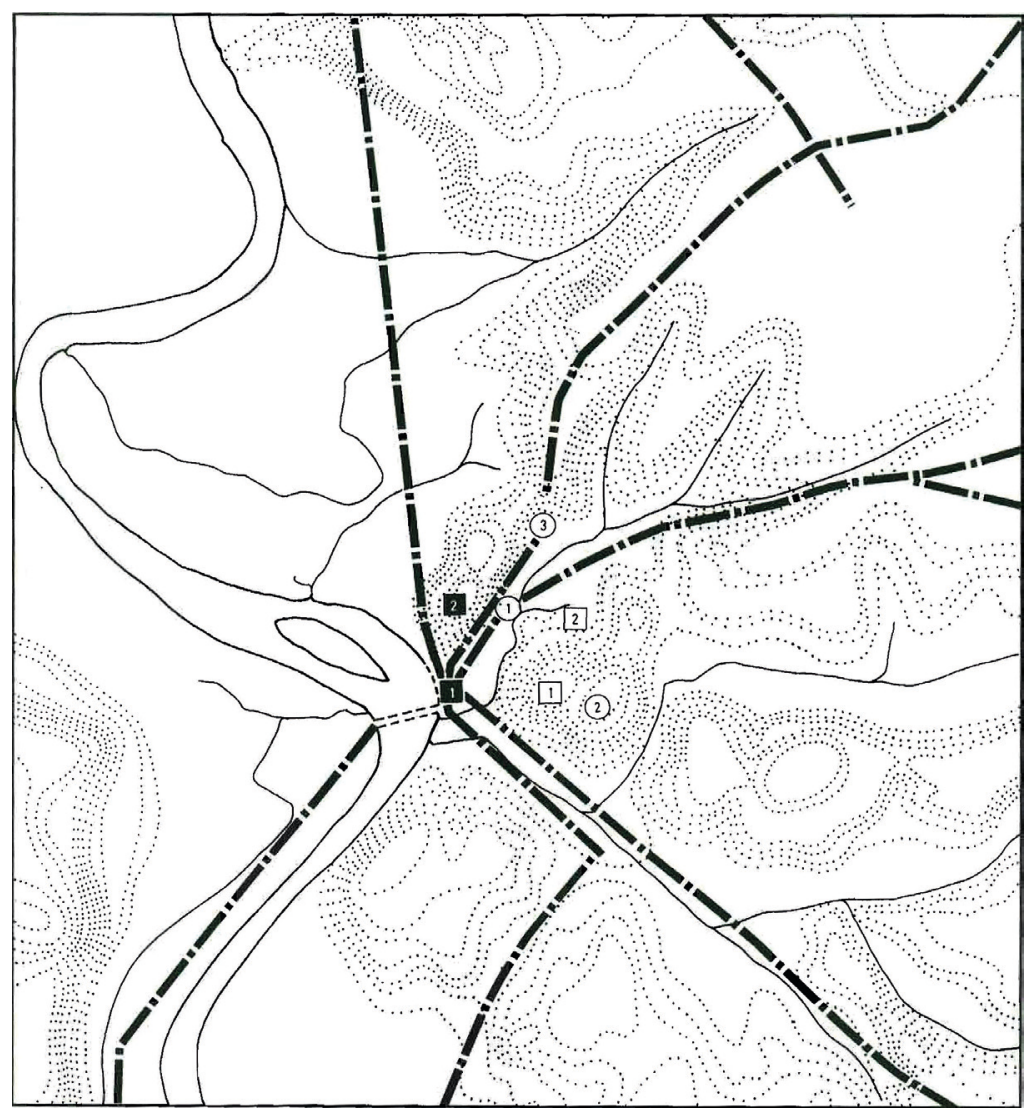

Fig. 1. La viabilidad prehistórica en el área de la ciudad de Roma (de Torelli, 2006, p. 578)

81 d.C. dedicada a Hércules proveniente, según P. Ligorio, de las inmediaciones del Ara Máxima en el Foro Boario ${ }^{35}$ (Fig. 1). Después de la libación, el pretor sacrificaba,

35. Herculi Victori / Pollenti Potenti / Invicto d(onum) d(edit) l(ibens) m(erito) / C(aius) [Vibi] us(?) Fronto / viator q(uaestorius) / dedic(atum) III K(alendas) Iul(ias) / L(ucio) Vettio Paullo / T(ito) Iunio Montano / co(n)s(ulibus). Comune di Roma, Musei Capitolini, Inventario Sculture, S $1962=$ CIL VI, 328 $($ pp 3004, 3756) $=$ ILS $3434=$ EDCS $17700095=$ EDR 121378. 
con la cabeza descubierta (graeco more) y una corona de laurel ceñida en la sien, ${ }^{36}$ una novilla al dios. ${ }^{37}$ Según un antiguo tabú, las carnes de la víctima debían de ser consumidas por entero en el interior del santuario ${ }^{38}$ por los fieles del culto, todos ellos exclusivamente varones sin excepción, que además comían sentados en el banquete ritual ${ }^{39}$ ceñidos también por coronas de laurel..$^{40}$ Este convivium se llevaba a cabo en varias ocasiones, durante la décima ofrecida por generales y mercaderes, antes del $\mu \xi \xi \sigma$ con el scortum del templo, e incluso durante los Ludi Romani en septiembre. En las grandes fiestas en honor al dios se distribuían entre los comensales significativas cantidades de carne. ${ }^{41}$ Además, la celebración del 12 de agosto se estructuraba en dos momentos: uno, por la mañana, donde se llevaba a cabo el sacrificio y otro, por la tarde, con la procesión de antorchas, tras lo que se ofrecían los exta al dios. ${ }^{42}$ Este largo e inusual intervalo de tiempo, unido al insoportable calor de verano, comprometía enormemente la conservación de los alimentos. Carne, queso y otros productos atraían a animales como las moscas ${ }^{43} \mathrm{o}$ los perros y es por ello que para conservarlos en buen estado se sometían a procesos de salazón. ${ }^{44}$ Así se explica el curioso poder que poseía el Hércules del Ara Máxima, pues dentro del recinto "es un prodigio divino que ni moscas ni perros entren en él pues mientras distribuía la carne entre quienes participaban de los sacrificios dícese que invocaba al dios Miagro, y que

36. Macrob., Sat. III 12, 2: “Vemos también una corona de laurel en la cabeza del pretor urbano, cuando sacrifica a Hércules”. Cf. Marcos Casquero, 2002, pp. 75-79.

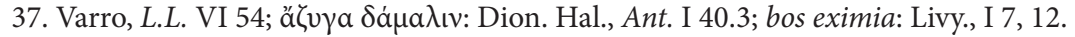

38. Varro, L.L. VI 54.

39. Serv., Aen. III 407; VIII 288; Macrob., Sat. III 6, 16-17.

40. Macrob., Sat. III 12, 1-4. En origen las coronas se elaboraban con hojas de álamo: "Por este motivo, nuestro Marón tomó acertadamente en consideración los tiempos en que Evandro, antes de la fundación de Roma, celebraba los sacrificios ante el Ara Máxima, haciendo uso del álamo, sin duda gratísimo al Alcida" (Macrob., Sat. III 12, 4). Cf. Marcos Casquero, 2002, pp. 75-79.

41. Bueyes, terneras, ciervos, carneros, machos cabríos, corderos, cabritos, cervatillos o pájaros, entre otros animales, eran aptos para ser inmolados en honor del dios (Marcos Casquero, 2002, p. 98).

42. Serv., Aen. VIII 269; Verg., Aen. VIII 282.

43. Ael., NA. V 17.

44. La sal se usaba comúnmente para deshidratar las piezas de carne e impedir el crecimiento de las bacterias encargadas de su descomposición (Moinier y Weller, 2015, pp. 119-120). Así lo indicaba Arist., [Pr.] 21, 5: "Por eso precisamente se conservan sin pudrirse los alimentos guardados en sal: pues por efecto de la sal se consume y se seca la humedad, que se pudre por el calor". Para conservar una pieza de jamón, por ejemplo, se necesitan entre 6 y 9 kilos de sal en relación con el tamaño de la pieza (Mangas Manjarrés y Hernando Sobrino, 2011, p. 11). Los ejemplos en la literatura clásica son múltiples: Plut., Symp. V 10, 3; Varro, Rust. II 4, 11; Verg., App. Virg. 55-59 o Plin., HN XXXII 27, entre otros. Una vez realizados los sacrificios, los sacerdotes podían o bien revender la carne sobrante en forma de embutidos o bien salarla para su posterior consumo (Moinier y Weller, 2015, p. 128). 
habiendo dejado la clava en la entrada de la capilla los perros huían nada más husmearla: hasta ahora perdura este fenómeno. ${ }^{45}$ Moscas y perros, animales de carácter ctónico y adversarios del propio Hércules, estaban también excluidos de santuarios griegos como los de Olimpia, Delos, Atenas Curio (Chipre), Pelene (Acaya) o Carma (Creta ${ }^{46}$ mientras que Miagro, en cambio, representa aquí un epíteto funcional del Zeus 'A el elemento esencial para el desarrollo de cualquier ritual dentro del culto del Hércules del Ara Máxima y su componente más arcaico y vertebrador de cualquier mito o leyenda relacionado con el Foro Boario. ${ }^{48}$

La investigación arqueológica en la ciudad de Roma ha sido capaz de identificar, con bastante probabilidad, los restos del Ara Máxima del Foro Boario en la cripta de la iglesia de Santa María in Cosmedin, también llamada de Schola Graeca, del siglo VI. Fechables a mediados del siglo II a.C., formarían parte del programa evergético y propagandístico de Publio Cornelio Escipión Emiliano proyectado para la reconstrucción del Foro Boario durante su censura en el 142 a.C. ${ }^{49}$ debido a su destrucción en el 213 a.C. durante un incendio. ${ }^{50}$ Según las fuentes clásicas, el Ara Máxima estaba compuesta por el altar propiamente dicho y un consaeptum sacellum, ${ }^{51}$ es decir, un fanum $^{52}$ o santuario sin aedes, con alrededor un muro para el temenos delimitado por termini o maceries. A nivel arqueológico, ${ }^{53}$ el edificio de Escipión consistía en un colosal podio en varios niveles de 35,50 x 23,70 x 4,40 m. de opus quadratum de bloques del Aniene ${ }^{54}$ revestido por placas de travertino y rodeado por un pavimento también de travertino. En el centro de este pódium se hallaba el ara propiamente

45. Solin., I 11. Cf. también Plin., HN X 29, 79; Plut., Quaest. Rom. 90.

46. Ail., Nat. V 17; Paus., V 14, 1; VII 27, 9-10; Plin., HNX 75; XXI 79; XXIX 106. También Eủpúvouoc, dios de la putrefacción, se representaba con la piel entre azul y negra, "como la de las moscas que se posan sobre la carne" (Paus., X 28, 7). Cf. Marcos Casquero, 2002, 92-95.

47. Paus., V 14, 1. Cf. también Clem. Al., Protr. II 38, 4 y Paus., VIII 26, 7.

48. Coarelli, 1988, p. 64; s.v. 'Hercules Invictus, ara Maxima', LTUR 3, 16; Marcos Casquero, 2002, pp. 79-86, 91-99; Torelli, 1993, pp. 105-108, 112-113; 2006, pp. 579-581. Cf. también recientemente Battaglini, 2016, pp. 51-64.

49. A cuyo esfuerzo por monumentalizar la zona se deben también la finalización del Pons Aemilius (Liv., XL 51,4) y la construcción del Aedes Aemiliana Herculis.

50. Serv., Aen. VIII 269-270.

51. Solin., I 10.

52. Tac., Ann. XV 41.

53. Para una discusión más detallada cf. Coarelli, 1988, pp. 61-77 y Torelli, 2006, pp. 590-616.

54. El uso extensivo de tufo del Aniene excluye cualquier fecha anterior al 144 a.C., año de inicio de los trabajos de construcción del Aqua Marcia, primer edificio público en toda Roma en utilizar dicho material (s.v. 'Hercules Invictus, ara Maxima', LTUR 3, 17). 
dicha, de planta circular según algunas acuñaciones del reinado de Antonino Pio y Caracalla. ${ }^{55}$ Probablemente existían una escalinata de acceso sudeste y otra noroeste, hacia donde se accedía también al consaeptum sacellum, donde se encontraba también, bajo un baldaquino tetrástilo, la estatua de culto del dios, copia muy probablemente de la del Hércules de Alba Fucens, y que fue pasto de las llamas en Julio del 64 d.C. durante el incendio neroniano ${ }^{56}$ además de las ya mencionadas maza y scyphus de madera. Alrededor de la estatua de culto, probablemente en el centro del sacellum, durante la fiesta del 12 de agosto se situaban los cargos de máximo prestigio $\mathrm{y}$ los senadores, sentados en cathedrae ${ }^{57}$ mientras que, en el banco exterior, del cual se ha podido excavar una pequeña porción nororiental, se sentaban los hombres del pueblo romano participantes del rito, donde recibían las hostiae, coronados por hojas de laurel, como hemos visto. De este modo el propio Hércules, personificado gracias a su ö $\gamma \alpha \lambda \mu \alpha$, participaba en el centro del banquete sagrado con los miembros de la sociedad romana más cercanos a él y el resto del pueblo romano más alejado, todos ellos consumiendo la carne del banquete, previamente conservada gracias a la sal, un regalo o donativo del propio dios. Por todo ello, era este imponente y arcaico edificio el centro del culto del Hércules del Foro Boario. Es probable que incluso el propio edificio albergase zonas para la conservación de los alimentos y de la propia sal, pero es tan sólo una conjetura que carece de más fuentes literarias o arqueológicas. ${ }^{58}$

\section{La vía Salaria: de Ostia a los Apeninos}

El culto de Hércules en Roma y el comercio de la sal no pueden entenderse completamente sin un estudio más detallado de la vía más antigua que partía de la ciudad de Roma, la vía Salaria. ${ }^{59}$ Los autores clásicos especifican que su nombre proviene del uso que los Sabinos le daban a esta ruta natural para abastecerse de la sal proveniente de las salinas de la costa tirrénica. ${ }^{60} \mathrm{La}$ sal era un componente esencial para las comu-

55. Cf. s.v. 'Hercules Invictus, ara Maxima', LTUR 3, 16.

56. Tac., Ann. XV 41.

57. Como en el caso de los fratres Arvales: "tatrastylum in cathedris consederunt et epulati sunt" (Torelli, 2006, p. 615).

58. ARA, pp. 429-430; Broughton, 1952, 1, pp. 474-475; 2, p. 555; Coarelli, 1988, pp. 61-77; DGRBM 3 , pp. 748-751; Ferenczy, 1976; s.v. 'Hercules Invictus, ara Maxima', LTUR 3, 16-17; RE 4.1, pp. 1439-1462; Palmer, 1965, pp. 293-324; Richardson, 1992, pp. 186-187; Torelli, 1993, pp. 113-114; 2006, pp. 590-616; Van Berchem, 1967, pp. 307-338.

59. Su antigüedad es generalmente aceptada incluso por los investigadores más hipercríticos. Cf. Coarelli, 1988, pp. 109-110.

60. Paul. Fest., 437 L; Plin., HN XXXI 89. 
nidades antiguas de la zona interior de la península itálica, de tradición ganadera y pastoril, que necesitaban la sal tanto para la alimentación como para la conservación de los alimentos frescos y el tratado de las pieles y otros productos derivados. Algunos autores apuntan a la existencia ya en época regia de un pacto entre Romanos y Sabinos que garantizaba el acceso de éstos a las salinas a través de la via Salaria, ${ }^{61}$ pero es indudable que, aun no existiendo tal acuerdo, el comercio entre las dos zonas, la costa y el interior, debía de tener lugar regularmente haciendo uso de las vías terrestres (via Salaria) o las vías fluviales (el Tíber) desde época muy anterior a cualquier mención histórica. Sus funciones, además de las estrictamente comerciales, tenían también que ver con la trashumancia del ganado desde los pastos de invierno de la llanura lacial hasta los de verano en la región de los Apeninos. Su funcionamiento, por tanto, se correspondía perfectamente con los atributos del Hércules del Ara Máxima, protector del ganado y de la sal. ${ }^{62}$

El trazado originario de la vía Salaria supone un reto para los historiadores, pues tan sólo algunos caminos conservan este nombre y su función inicial se ha visto superpuesta por otras necesidades conforme Roma iba creciendo y expandiéndose. El origen de la sal se encontraba en dos puntos diferentes. Desde las salinas de Ostia, en el margen izquierdo del Tíber, partía la vía Ostiensis, mientras que, desde el Campus Salinarum Romanarum, ${ }^{63}$ en el margen derecho, serpenteaba hacia el interior la vía Campana o vía Portuensis para otros autores. ${ }^{64}$ A su llegada a las inmediaciones

61. Hor., Epist. II 1, 25-26; Plin., HN XXXI 89.

62. Alvino, 2003, p. 7; Battaglini, 2005, pp. 67-68; Coarelli, 1981, p. 184; 1988, pp. 109-110; Coarelli y La Regina 1984, p. 87; Giovannini, 1985, pp. 373-374, 382-383; s.v. 'Salaria via', LTURS 5, 35; Moinier y Weller, 2015, pp. 275-276; SR 1, pp. 133-134.

63. Para la bibliografía clásica sobre el Campus Salinarum Romanarum cf. Fea, 1831 y Lanciani, 1888, pp. 83-91. Para la bibliografía moderna: Olcese y Zevi, 2004, pp. 43-55. Recientemente los arqueólogos han identificado, poco al sur de esta área, un edificio, datado desde el siglo I a.C. hasta el siglo II d.C., que probablemente estuviese destinado a funciones de servicio (almacén, oficina o residencia de los trabajadores) y estrechamente relacionado con las actividades que se desarrollaban en las salinas. En su interior se encontraron dos grandes bloques fragmentados en travertino; uno de ellos lleva en el frente una inscripción dedicada a Neptuno por dos conductores Campi Salinarum Romanarum: Neptuno / sacrum / ca $<m=P>$ pi salinar(um) / Romanar(um) / L(ucius) Virtius / Epaphroditus et / L(ucius) Cornelius / Hesper / conductores / dedicatus / Pontiano et / Atiliano co(n)s(ulibus). AE 2014, 264 =EDCS 71200588. Para el epígrafe cf. Cebeillac-Gervasoni y Morelli, 2014, pp. 23-33. Para su contexto arqueológico cf. Morelli y Forte, 2014, pp. 9-21.

64. Cf. Moinier y Weller, 2015, p. 64, fig. 6. Coarelli tan sólo considera esta última vía como la continuación natural de la vía Salaria arcaica. En esta vía, además, se ubicarían algunos de los santuarios más antiguos, como el de Fors Fortuna y Dea Dia, fechables entorno a los siglos VII y VI a.C. (Coarelli, 1988, p. 113). 
de Roma, esta última cruzaba el río a través del pons Sublicius o del paso natural de la isla Tiberina y continuaba hacia el Noreste hacia el interior, al igual que hacía su homóloga vía Ostiense por el Velabro. El control de este paso, por tanto, se convirtió en prioritario ya desde muy antiguo, lo que coincide con el desarrollo a partir del 1600 a.C. del primer asentamiento estable en la colina Capitolina. ${ }^{65}$ En su recorrido intraurbano, las diferentes reestructuraciones tardorrepublicanas posteriores borraron los rastros originarios del trazado arcaico, pero los arqueólogos modernos han sido capaces de distinguir entre una Salaria vetus y una Salaria nova, más moderna. La primera partía entonces desde la Porta Pinciana de época aureliana hasta la ciudad de Antemnae (Monte Antenne), mientras que la segunda hacía lo propio desde la Porta Collina republicana y después desde la Porta Salaria aureliana y llegaba, en origen, hasta Reate (Rieti), pasando por territorio sabino. ${ }^{66}$ Tras la conquista de esta zona en el 290 a.C. por Marco Curio Dentato, la vía se amplió hasta Castrum Truentinum, en el Adriático, para permitir la comunicación entre las dos costas y el interior montañoso. ${ }^{67}$ En el siglo XIX el descubrimiento en Porta Collina de un epígrafe en referencia a una supuesta vía Caecilia, datado entre los años 88 y 77 a.C. ${ }^{68}$ ha puesto en relación a ésta con la Salaria, y algunos autores afirman que ésta sería la vía que, desde Amiternum (San Vittorino Amiterno), continuaría la antigua vía Salaria con sus productos hasta el mar Adriático. ${ }^{69}$

En el siglo III d.C. la muralla Aureliana dividió en dos partes una antiquísima zona funeraria en uso desde finales del siglo VIII a.C. que estaba situada entre las dos Salarias, justo en el primer kilómetro de las mismas, entre las puertas Pinciana y Salaria. ${ }^{70}$ Las excavaciones in situ en Piazza Fiume llevadas a cabo desde el siglo XVIII

65. Para el contexto arqueológico cf. ARA, p. 149; Carandini, 1997, p. 113; Cazzella, 2001, pp. 265268; Filippi, 2005, pp. 93-115; Fugazzola Delpino, 1976, tav. IIB, d, f, g; Lugli, 1985, pp. 289-294; SR 1, pp. 135-136.

66. Cf. s.v. 'Salaria via', LTURS 5, 35-44 para la discusión de las hipótesis y las fuentes propuestas hasta la fecha.

67. Para el recorrido de la vía consular cf. Itinerarium Antonini y Tabula Peutingeriana.

68. CIL VI, 40904a = CIL VI, 3824 (p. 3134, 3799) = CIL VI, $31603=C I L \mathrm{I}^{2}, 808$ (p. 954) =ILS 5799 $=\operatorname{ILLRP} 465$ (p. 332) = AE 1995, $90=$ AE 2000, $254=$ AE 2012, $297=$ EDCS $1000017=E D R 093205=$ EDH 016035.

69. Cf. s.v. 'Salaria via', LTURS 5, 37 para la discusión. Alvino, 2003, pp. 7-12; ARA, p. 149; Battaglini, 2005, pp. 68-69; Carandini, 1997, p. 113; Cazzella, 2001, pp. 265-268; Coarelli, 1981, p. 184; Filippi, 2005, pp. 93-115; Fugazzola Delpino, 1976, tav. IIB, d, f, g; s.v. 'Salaria via', LTURS 5, 35-44; Lugli, 1985, pp. 289-294; Moinier y Weller, 2015, p. 64; SR 1, pp. 133-134.

70. Para un tratamiento más en profundidad cf. s.v. 'Salaria via', LTURS 5, 38-40. 


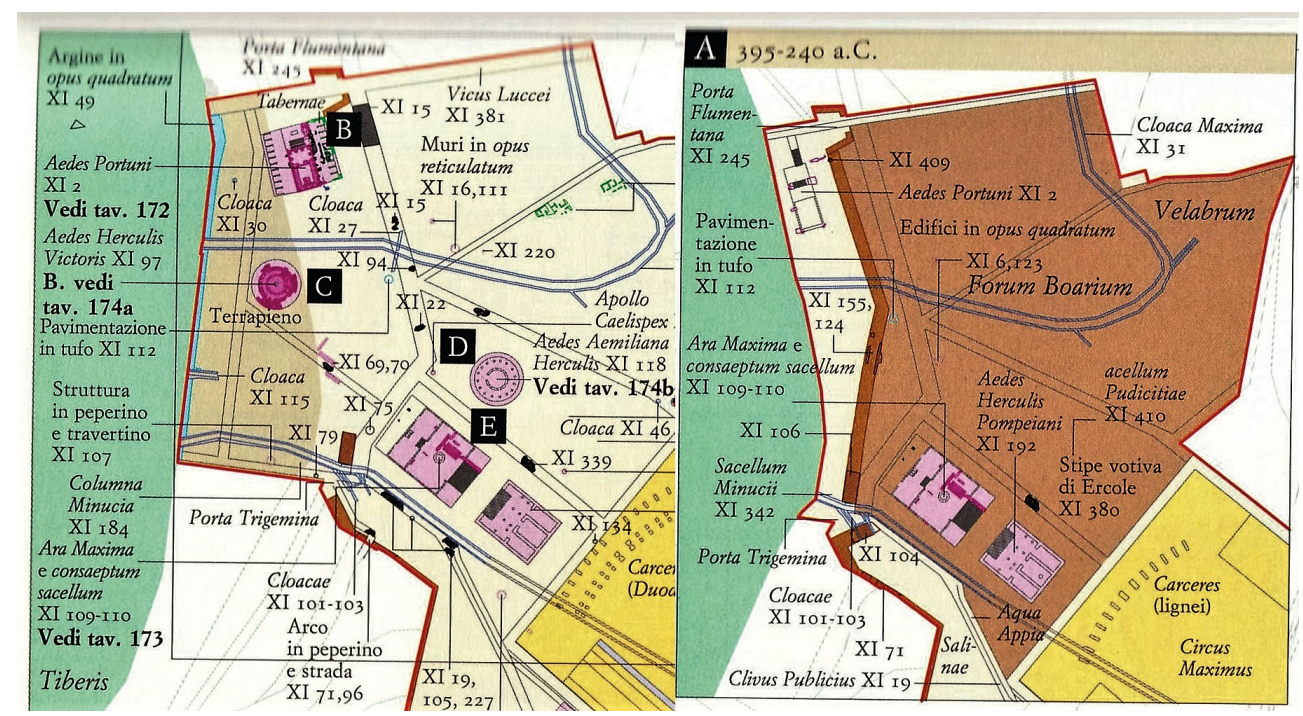

Fig. 2. El Foro Boario entre los años 395-240 (dcha.) y 240-27

a.C. (izda.) (de $A R A$, Tav. 171)

sacaron a la luz tres epígrafes de gran relevancia, dos de ellos sepulcrales ${ }^{71}$ y el tercero un ara votiva, datada en el siglo I d.C. ${ }^{72}$ (Fig. 2). El conjunto se interpreta como un sacellum consagrado a Hercules Primigenius, un Hércules cuyo epíteto es especialmente raro y desconcertante en Roma, ya que no tiene otros paralelos en la ciudad y parece asociarse de algún modo con el culto de Fortuna Primigenia en Praeneste (Palestrina), a pocos kilómetros al Este de la Urbs. ${ }^{73}$ Sin embargo, la ubicación donde fueron halladas las piezas, muy cercana a la puerta y vía Salarias, estaría posiblemente significando un tipo de culto a Hércules, quizás muy antiguo, relacionado de algún

71. Sex(tus) Clodius Sex(ti) l(ibertus) Amoenus / eborarius ab Hercule / Primigenio. CIL VI, 7655 (p. 3432, 3852) = ILS $7707=$ EDCS 18600375; y P(ublius) Saenius / P(ubli) (mulieris) l(ibertus) Arsaces / $m<i=E>n<i=E>$ strator ab (!) / Hercul(e) Primig(enio) / Petronia (mulieris) l(iberta) / Fausta $c<o=V>n c($ ubina) / Petronia P(ubli) C(ai) (mulieris) l(iberta) / Digna. CIL VI, $9645=$ EDCS 19301187.

72. Herculi / Primigenio / sacrum / C(aius) Petronius / C(ai) f(ilius) Vel(ina) / Paetus f(ecit). Comune di Roma, Musei Capitolini, Inventario Sculture, S82 = CIL VI 30907 (p. 3758) = ILS $3433=$ EDCS $18600467=E D R 121241$.

73. Alvino, 2003, pp. 17-22; s.v. 'Hercules Primigenius', LTUR 3, 21; s.v. 'Salaria via', LTURS 5, 38; Richardson, 1992, p. 188. 
modo con el lugar, que con el paso del tiempo quizás sólo se recordaba mediante el epíteto Primigenius, que da de nuevo una idea de prístino, primigenio, primitivo. Desde luego un culto a Hércules junto a una vía donde pasaban diariamente la sal y el ganado provenientes de Roma resulta perfectamente plausible, y más si contrastamos también lo que nos cuentan las fuentes clásicas. Suetonio, en su vida de Vespasiano, nos cuenta que junto a la vía Salaria se hallaba la supuesta tumba de un compañero de Hércules, cuyo nombre desconocemos. ${ }^{74} \mathrm{El}$ inciso del autor nos confirma que junto a la vía existía un cierto culto y memoria del dios dorio, que pudo transformarse con el paso del tiempo pero que nunca llegó a olvidarse del todo.

Una situación muy similar parece verificarse también en la ciudad de Ostia Antica. ${ }^{75}$ Hacia el Sur, la vía Salaria llegaba hasta la colonia romana por medio de la vía Ostiensis y allí formaba un cruce con la vía Salaria Albana, posteriormente denominada vía Laurentina, que permitía también a los habitantes de los montes Albanos disfrutar de las salinas de la desembocadura del Tíber y de todos sus productos asociados. Los estudios de la topografía medio-republicana del castrum originario de Ostia ${ }^{76}$ demuestran cómo esta singular característica se manifiesta aún en el parcelario primitivo del enclave: el cardo máximo sigue el antiguo trazado de la Salaria Albana, gracias a vía Laurentina y vía della Foce, mientras que el decumano máximo sigue a la Salaria Sabina por medio de la vía Ostiensis y el segundo tramo del decumano. Justo en coincidencia con estas dos rutas arcaicas, surge, en época difícil de precisar, un santuario dedicado a Hércules, posiblemente de carácter compitalicio. ${ }^{77}$

74. Suet., Vesp. 12, 1: comitemque Herculis, cuius monimentum extat Salaria uia.

75. Cf. el artículo de Coarelli en SR 1, pp. 136-143 para la discusión sobre los orígenes de la ciudad. Para la zona del ager portuensis cf. Morelli, Forte y Carbonara, 2008, pp. 213-232; Morelli, 2011, pp. 4765; Morelli, 2014, pp. 52-71. Para la zona de la Isola Sacra cf. Baldassarre, Bragantini y Morselli, 1996 y Cébeillac-Gervasoni, 2013, pp. 241-249.

76. Para más detalles del contexto arqueológico cf. Zevi, 2002a, pp. 13-58 y Zevi, 2002b, pp. 11-32. Para el contexto cerámico cf. Olcese 2017a y Olcese, 2017b, pp. 197-224.

77. Entre los diversos indicios aducidos para sostener esta hipótesis está el del posible traslado del compitum originario del santuario por orden de C. Cartilius Poplicola a mediados del siglo I a.C. como menciona CIL XIV $4710=I L S 5395$ (p. 185) = AE 1892, $142=A E$ 1893, $24=$ EDCS 11900486 = EDR 106925: Po[st]umus Plotius M(arci) f(ilius) Quarto / A(ulus) Genucius A(uli) f(ilius) iter duoviri / locum dederunt compiti aedificandi / C(aius) Cartilius C(ai) f(ilius) Poplicola duovir VII / cens(or) III compitum transtulit / D(ecimus) Caecilius DD(ecimorum) l(ibertus) Nicia medicus / L(ucius) Marcius L(uci) l(ibertus) Stephanus / P(ublius) Naevius P(ubli) l(ibertus) Heraclida / mag(istri) vici maceriem I et columnam de suo fecerunt / C(aius) Cartilius C(ai) l(ibertus) Hera[cleo]. Según Giovanni Becatti y Ricardo Mar, además, la antigüedad del culto se pone de manifiesto iconográficamente a través de la identificación de Hércules-Melkart en el relieve marmóreo votivo de C. Fulvius Salvius: C(aius) Fulvius Salvis haruspex $\{s\} d($ onum $) d($ at $) / /[S]$ ort (es) H(erculis). CIL I $3027=I L L R P 128$ (p. 320) = AE 1941, 67 


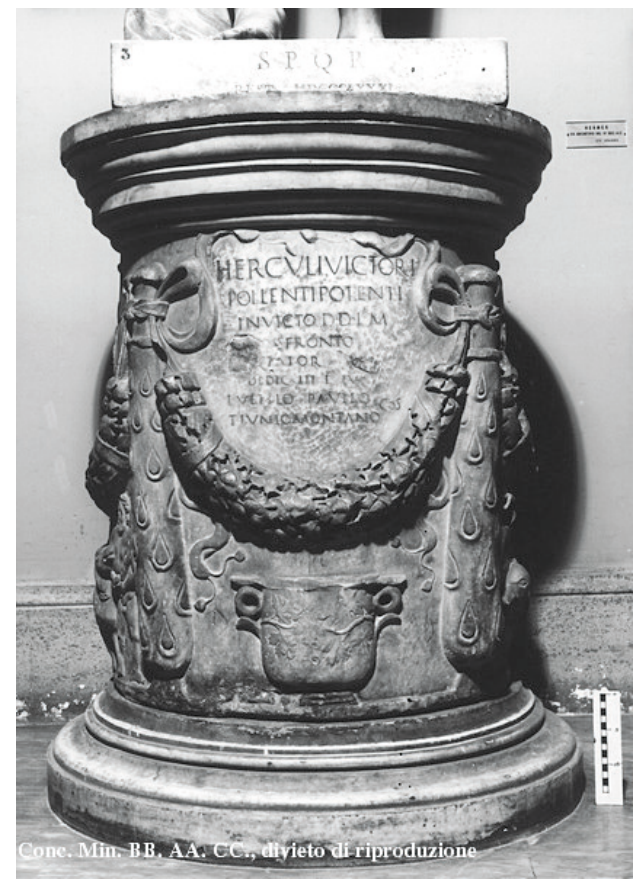

Fig. 3. Base circular dedicada a Hércules proveniente del Foro Boario (de EDR 121378)

La presencia de la actividad económica en las salinas cercanas, junto a la existencia del Hércules del Ara Máxima en Roma, parece indicarnos que este culto local también podría tener que ver con la sal, dada su antigüedad y ubicación especiales, y estaría encargado de satisfacer las necesidades religiosas tanto de los comerciantes como de los habitantes y trabajadores de la zona. ${ }^{78}$ Desde el siglo II a.C. este culto se hace tangible mediante la construcción de un templo dedicado al dios dorio en cuyo temenos se alojan también otros edificios como el Templo Tetrástilo, el Templo del Ara Redonda y otros edificios anexos ${ }^{79}$ (Fig. 3).

$=A E$ 1971, $72=$ EDCS $15700058=E D R 73462=E D H$ 21282. Para el contexto epigráfico de la ciudad portuaria cf. Cébeillac-Gervasoni, Caldelli y Zevi, 2010.

78. En cualquier caso, en su desarrollo posterior, el culto adquiere unas características oraculares como lo demuestran los restos arqueológicos e iconográficos hallados in situ. Cf. Becatti, 1939, pp. 3758. En cuanto a la función del templo en época republicana e imperial, Zevi se inclina por un uso militar mientras que Coarelli lo hace por un uso principalmente comercial y portual. Cf. Pavolini, 2006, p. 119.

79. Becatti, 1939, pp. 37-58; Mar, 1990, pp. 137-149; Pavolini, 2006, pp. 20-22, 26-30, 117-121; Zevi, 2012, pp. 537-563. 


\section{LOS SANTUARIOS DEL DIOS EN EL CENTRO DE ITALIA}

Como acabamos de ver, la Vía Salaria, desde la Edad del Bronce, representa el eje fundamental del comercio entre las salinas y productos comerciales de la costa y el interior de la península, junto con la trashumancia de ovejas, bueyes y otros animales. ${ }^{80}$ De todos estos bienes es dios el Hércules itálico, que hemos visto ya para los casos de Ostia Antica y Roma, en el Foro Boario y en las inmediaciones de la propia Salaria. Las rutas trashumantes y el culto de Hércules son dos elementos fuertemente ligados desde hace ya tiempo en la investigación ${ }^{81}$ y que encuentran numerosos paralelos por todo el centro y sur de Italia. ${ }^{82}$ Los pastores se movían desde las llanuras $o$ los valles en otoño e invierno hasta la montaña en primavera y verano ${ }^{83}$ Las rutas que seguían, denominadas tratturi o calles publicae, formaban una red comercial por toda la península a la que se asociaban, diseminados por todo el trayecto, los santuarios dedicados al dios itálico. Estos lugares de culto proveían a los cansados pastores y a sus reses de alojamiento, protección, reabastecimiento y, por supuesto, de lugares de mercado donde ofrecer e intercambiar sus productos, entre ellos la sal, como pasaba en Roma. Pero no sólo los pastores y sus reses visitaban frecuentemente estos lugares sagrados. Peregrinos, comerciantes y personajes importantes de la oligarquía local, como en el Foro Boario en Roma ${ }^{84}$ financiaban y dedicaban al dios itálico ex votos, estatuas e incluso santuarios enteros en gratitud o para cumplir un voto o una petición realizada en momentos de necesidad. A partir de los siglos III y, sobre todo, II a.C., se puede percibir en territorio peninsular una creciente popularidad por el Hércules itálico, ya por entonces imbuido de la mitología y las influencias helenizantes. La difusión del culto por Italia central está muy bien testimoniada gracias a los innumerables ejemplos conocidos, entre los cuales destacan el santuario dedicado a Hércules en el centro daunio de Teanum Apulum (San Paolo di Civitate), el santuario rural de los siglos V-III a.C. de Pescosansonesco, el estípite votivo de Caramanico con varias estatuillas del dios cerca de la iglesia de San Tommaso di Salle, el santuario

80. Como por ejemplo también los équidos (Van Wonterghem, 1999, p. 413).

81. Cf. Balty, 1964, pp. 45-54.

82. También en Hispania parece repetirse, con increíble semejanza, esta misma dinámica. Cf. recientemente Hernando Sobrino, 2014, pp. 383-411. Para el caso de Etruria cf. Carusi, 2008, pp. 303312.

83. Existía, por tanto, una trashumancia de tipo vertical y otra de tipo horizontal (Van Wonterghem, 1999, p. 413).

84. Cf. p. ej. el aedes Herculis Victoris ad Portam Trigeminam, mandado construir a mediados del siglo II a.C. por M. Octavius Herennus, según Macr., Sat. III 6, 9 rico comerciante tiburtino que había sido salvado por el dios de unos piratas durante un viaje de negocios ( $A R A$, p. 429; s.v. 'Hercules Victor, aedes (ad portam Trigeminam)', LTUR 3, 22-23; Palmer, 1990, pp. 234-240; Ziolkowski, 1988, pp. 309-333). 
de Hercules Iovius en Incerulae (Navelli), el santuario urbano de Peltuinum (Prata d'Ansidonia), el santuario de Hércules del Pagus Fificulanus de Onna (Paganica), el de Hercules Curinus en Monte Morrone, cerca de la antigua Sulmo (Sulmona), los de Pietrabbondante y Vastogiradi o también el forum pecuarium de Saepinum (Altilia, Sepino), donde se hallaron estatuillas de bronce y fragmentos de estatuas imperiales de mármol del propio dios. ${ }^{85}$ Tremendamente significativo es también el hecho de que varias de estas calles publicae pasaban por zonas de salinas como en los casos de Salapia (Salpi, Cerignola, Puglia), las desembocaduras del Trigno y del Sangro en Molise, o en Montesilvano (Abruzzo). La sal desempeñaba, por tanto, en esta red comercial una importancia capital en el comercio entre los diversos pueblos, con varias zonas de abastecimiento del mineral y, muy posiblemente también, varias calidades de sal diferentes. Todo ello, por supuesto, bajo la tutela de Hércules. Lo atestigua, por ejemplo, la presencia del Hercules Ranus en el santuario samnita de Campochiaro, en Molise. ${ }^{86}$ En este lugar de culto del dios itálico, ${ }^{87}$ punto de paso obligado desde el Samnio a los pastos invernales de Apulia y las salinas de Salapia, las fuentes ${ }^{88}$ mencionan ofrendas votivas como mola, vino, agua o rano, este último interpretado como "sal molido". ${ }^{9}$ Si esta propuesta es correcta, el Hercules Ranus sería la versión samnita del Hercules Salarius, dios específicamente tutelar de la sal y venerado en el importantísimo santuario de Alba Fucens. ${ }^{90}$

La colonia latina de Alba Fucens (Albe, Massa d'Albe), deducida en el 303 a.C. tras una violenta guerra contra los Equos ${ }^{91}$ y en pie hasta su definitiva transformación medieval en el siglo VI d.C., albergaba un vasto complejo público formado por un foro y su pórtico, una basílica, un mercado posteriormente reconvertido en termas y un enorme santuario dedicado a Hércules. Este último se trataba fundamentalmente de una inmensa área porticada, alargada de norte a sur, con unas dimensiones de $83,93 \times 36,60 \mathrm{~m}$ al norte y otros 34,73 al sur, y que finalizaba en su eje noroccidental en una cabecera o sacellum de 14,25 x $5 \mathrm{~m}$. Los pórticos laterales dúplices, por su parte, medían 12,30 m de largo y se sujetaban mediante columnas de latericium estu-

85. Cf. Van Wonterghem, 1999, pp. 416-426 para una lista más completa.

86. Identificado por primera vez por La Regina, 1976, pp. 219-254. Sobre el lugar vid. también recientemente Scopacasa, 2015, p. 194.

87. Atestiguado por la presencia de estatuaria y varias inscripciones dedicadas a Hércules. Cf. Capini y Di Niro, 1991, pp. 115-120.

88. Fundamentalmente las tabulae Peutingeriana e Iguvinae (Torelli, 1993, p. 116).

89. Según Prosdocimi, 1978, pp. 585-788.

90. Stek, 2009, pp. 55-58; Torelli, 1993, pp. 116-117; Van Wonterghem, 1999, pp. 413-428.

91. Livy., IX 45; Cass. Dio, XX 101. 
cadas, que daban paso a las entradas al recinto, una al sur, una al oeste y otra al este, en correspondencia con el eje viario, todas ellas en ligera pendiente para consentir el paso de carros, mulas y ovejas. Es por ello que los investigadores se decantan por definir el espacio como forum pecuarium, es decir, como un mercado ovino, ${ }^{92}$ con una capilla dedicada a Hércules en su cabecera para proteger y ofrecer un lugar de culto a los pastores y comerciantes que acudían al centro comercial y mediar como garante en las transacciones comerciales que allí se efectuaban. ${ }^{93}$ Este sacellum, en una fase más reciente comunicante con los dos ambientes laterales, se componía de tres ambientes a juzgar por el pavimento en mosaico bícromo de época republicana conservado in situ: ${ }^{94}$ un vestíbulo, una zona central más grande y una pequeña área rectangular al fondo del sacellum con dos columnas y dos semi-columnas dóricas, ${ }^{95}$ muy probablemente sujetando un baldaquino, edícula o ciborium $^{96}$ (Figs. 4 y 5).

En esta misma zona del santuario se hallaron ${ }^{97} 14$ fragmentos relativos a una estatua monumental ${ }^{98}$ de Hércules en mármol blanco de proveniencia griega, ${ }^{99}$ probablemente realizada para el sacellum mismo por un taller neoático de modesto nivel y datada a finales del siglo II o principios del siglo I a.C. (Fig. 6). El dios, de edad madura, está sentado sobre un trono posiblemente de madera o de otro material, con la pierna izquierda ligeramente adelantada respecto a la derecha. En el brazo izquierdo,

92. Y no como macellum, como otros investigadores proponen. Para la discusión cf. Coarelli y La Regina, 1984, p. 87.

93. Además de la perceptible inclinación del plano de las entradas del complejo, otros argumentos defienden la tesis del forum pecuarium, como p. ej. la proximidad del complejo a las murallas y a una puerta de la misma, lo que facilitaría el tránsito comercial y reduciría las molestias (ruido, olores, etc.) para los habitantes de la comunidad de Alba Fucens (Coarelli y La Regina, 1984, p. 87).

94. En una posición muy cercana a la puerta de entrada aún se conservaba de forma fragmentaria la inscripción del donante del edificio: $L$ (ucius) Vettius Q(uinti) f(ilius) Ter(etina) [---]. CIL I $3274=A E$ 1962, $31=A E$ 1964, $204=A E 2006,382=E D C S 12800340=E D C S 13400016=E D R 74285=E D H$ 16489.

95. Diámetro 49,50 cm (De Visscher, 1962, p. 12).

96. Coarelli y La Regina, 1984, pp. 84-87; De Visscher, 1962, pp. 9-15; EAA, pp. 192-194; Liberatore, 2004, pp. 13-21, 36-37; Mertens, 1981, pp. 41-42; Torelli, 1993, pp. 111-115. En la antigua ciudad africana de Leptis Magna también se encuentra un templo dedicado a Hércules con características compartidas con el de Alba Fucens. Cf. para más detalles Torelli, 2015, pp. 257-260.

97. Del 28 de mayo al 30 de junio de 1960, en el curso de las excavaciones realizadas por la Academia Belga de Roma a las órdenes de F. De Visscher, F. De Ruyt y J. Mertens (De Ruyt, 1982, p. 123; De Visscher, 1962, p. 15; Liberatore, 2004, pp. 36-37).

98. Medidas: altura $2,40 \mathrm{~m}$, cabeza $46 \mathrm{~cm}$, longitud total $1,40 \mathrm{~m}$, longitud brazos $75 \mathrm{~cm}$, longitud mano derecha $15 \mathrm{~cm}$, longitud piernas $75 \mathrm{~cm}$ (De Ruyt, 1982, p. 122).

99. Lo indican las letras del alfabeto griego П y $\mathrm{P}$ grabadas en la espalda del torso de la figura (De Ruyt, 1982, p. 124). 

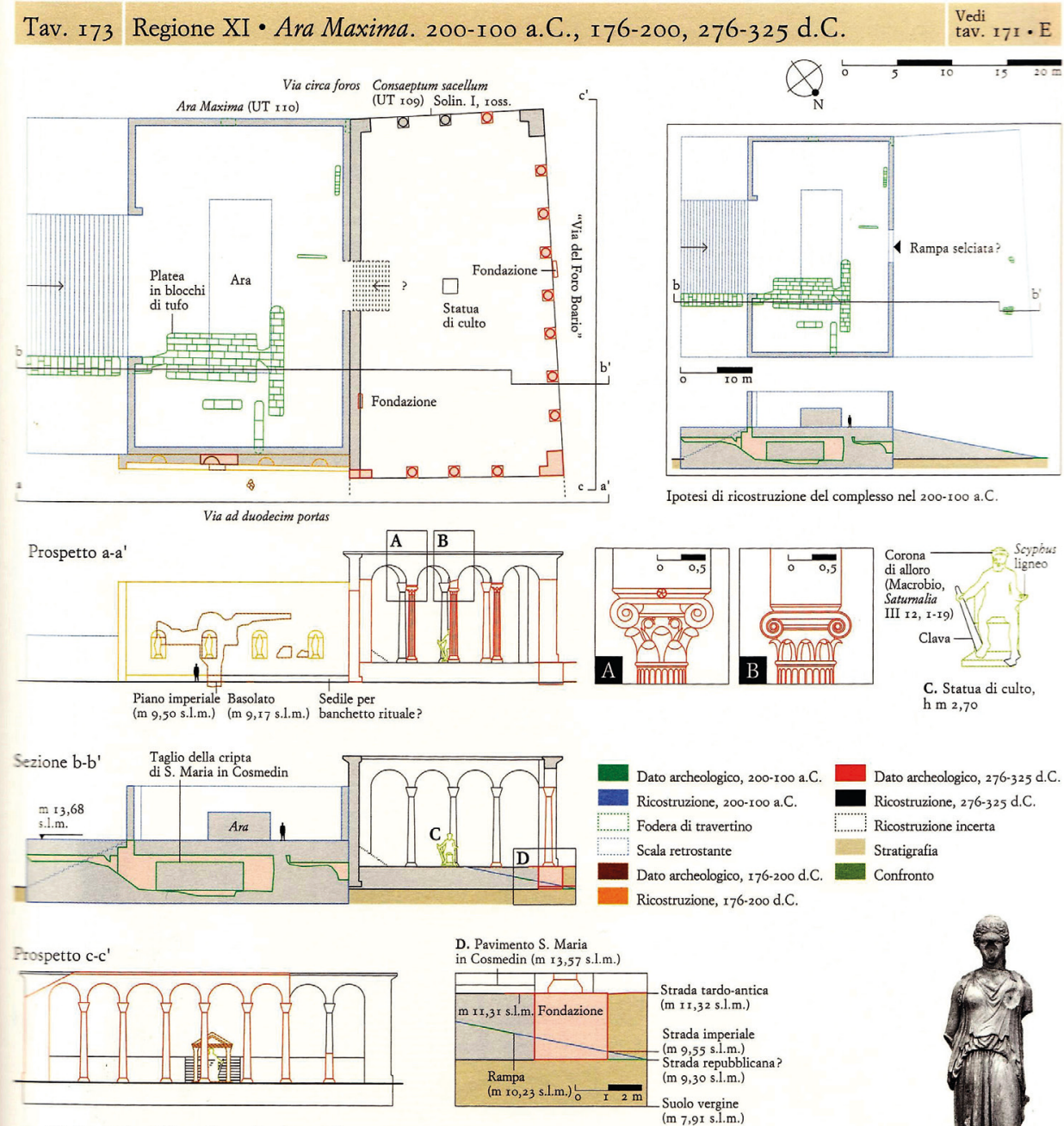

lyocesi di ricostruzione del complesso nel r 76-200 d.C.
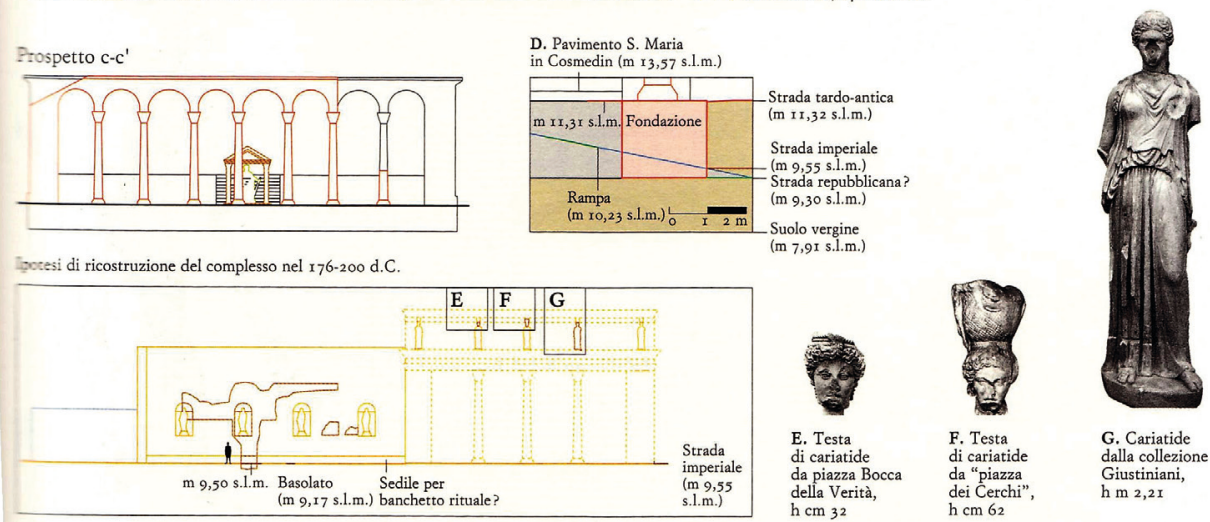

Fig. 4. Ara Maxima Herculis. 200-100 a.C., 176-200, 276-325 d.C. (de ARA, Tav. 173) 


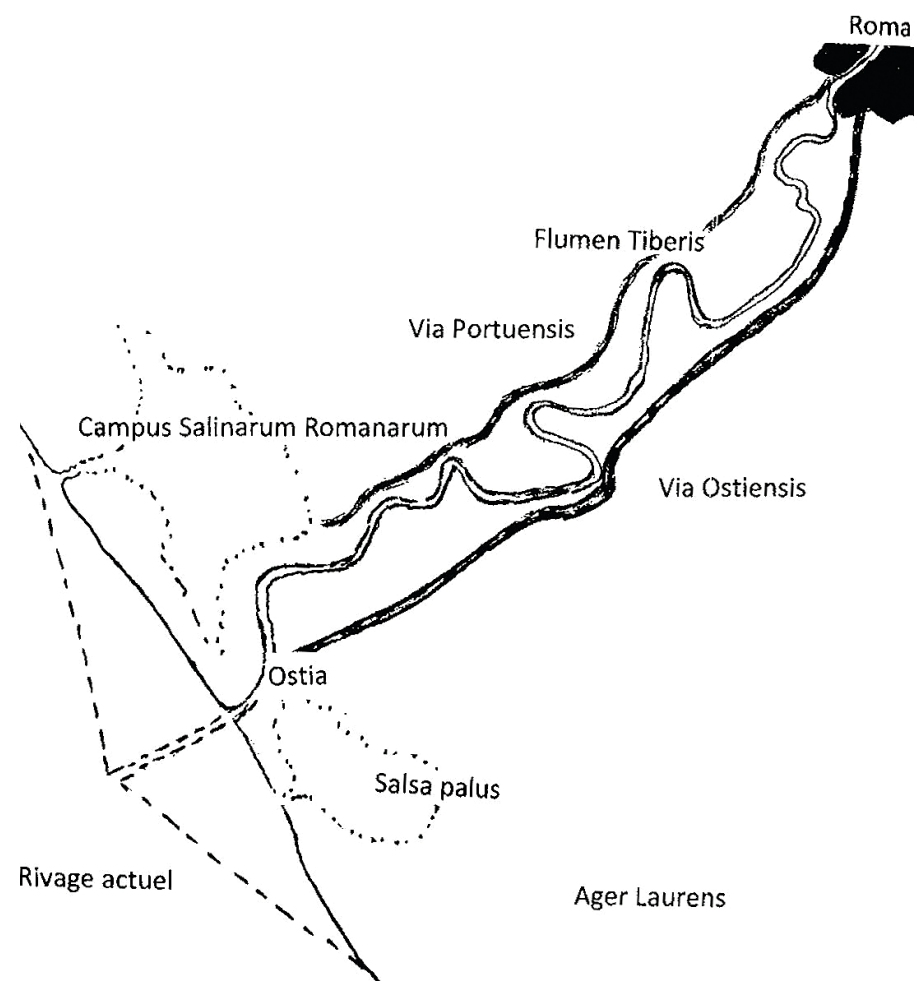

Fig. 5. Localización de las marismas salinas de Ostia (de Moinier y Weller, 2015, p. 64)

ligeramente atrasado, sujeta el scyphus, mientras que el derecho está apoyado sobre la maza, que no conservamos y que estaría también realizada en otro material. Viste asimismo la $\lambda \varepsilon o v t \varepsilon ́ \eta$ propia del dios y visible aún en el brazo izquierdo, además de ceñirse en la cabeza con una corona de laurel, con los foros todavía visibles para algún tipo de encaje en otro material. La crítica adscribe el modelo a una versión tardía

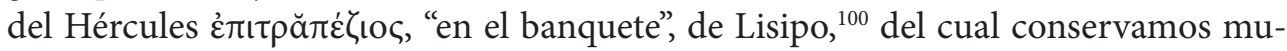
chas variantes, ${ }^{101}$ con la maza, el scyphus o las manzanas de las Hespérides, según la

100. Cf. De Visscher, 1962, pp. 15-69 para una discusión más detallada.

101. Para una lista detallada de la mayoría cf. s.v. 'Herakles', LIMC 4.1, pp. 772-777 y De Visscher, 1962, pp. 59-69. Cf. también Di Felice y Torrieri, 2006, p. 306. 


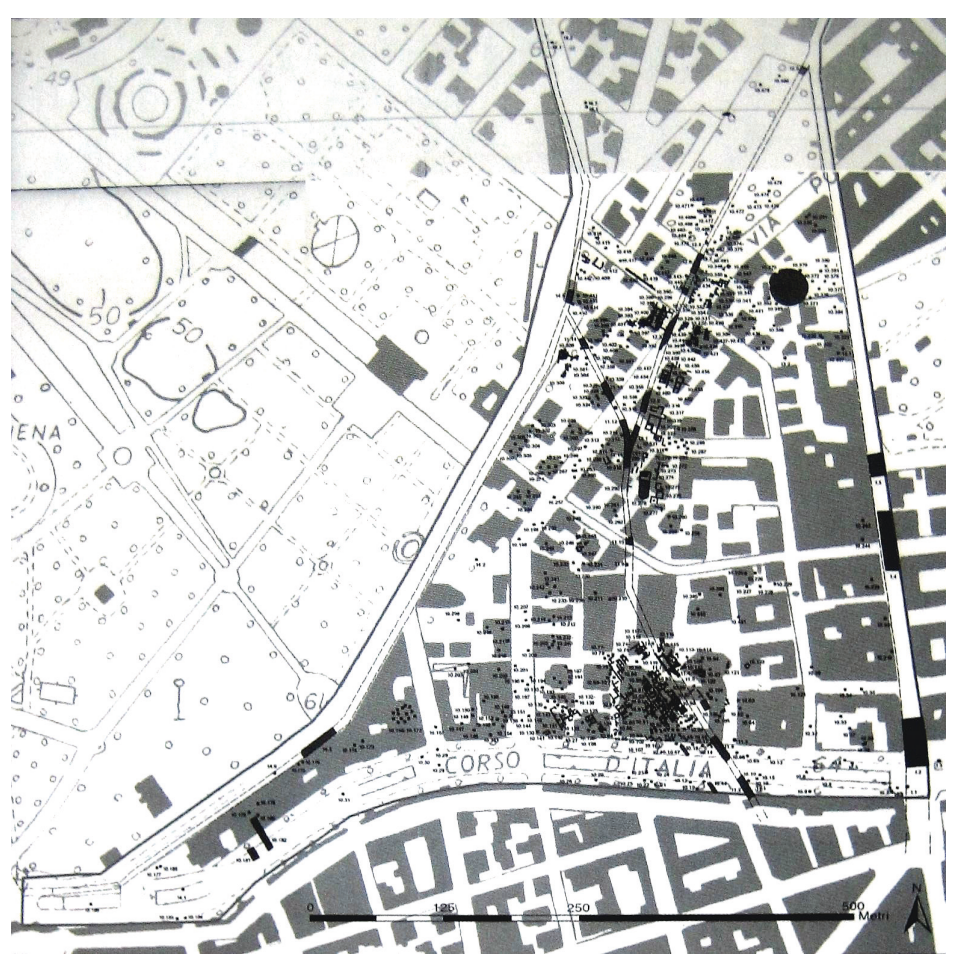

Fig. 6. Plano arqueológico de la zona del Sepolcreto Salario (de LTURS V, 290)

versión. ${ }^{102}$ Pero más importante aún es el hecho de que encontramos en esta escultura todos los atributos que hemos podido apreciar en las fuentes para el Hércules del Ara Máxima: la corona de laurel, el scyphus, la postura sentada, la posición debajo de un baldaquino tetrástilo o la misma localización del sacellum en un forum pecuarium, que bien puede evocar la voluntad empórica y comercial del Foro Boario en Roma, como pudimos ver. Incluso la fecha probable de adscripción de la estatua, a finales del siglo II a.C., junto a su estilo, de moda durante la segunda mitad de ese mismo

102. Uno de los mejores y más completos ejemplares, muy similar al de Alba Fucens, se encuentra en el Museo Nacional de Nápoles, inv. 2828. Fechado en el siglo I a.C., su estado de conservación es tan excepcional que conserva íntegros los objetos que apenas percibimos en el de Alba Fucens, incluidos el scyphus y la maza. Cf. De Visscher, 1962, p. 65. 
siglo, se asemeja poderosamente a la fecha de restitución del Ara Máxima durante la censura de Escipión Emiliano, como pudimos apreciar. Todo ello ha llevado a los especialistas a considerar que quizás nos encontremos ante un simulacro del dios igual o parecido al del Ara Máxima en el Foro Boario, ${ }^{103}$ mandado realizar para el santuario romano por el proprio Escipión y después replicado en otros santuarios del mismo tipo, como es el caso de Alba Fucens. La relación del dios con la sal es en este caso aún más explícita. Un ara erigida en honor del liberto Tito Camerio Apto por la cofradía de religiosos a cargo del culto del Hércules de Alba Fucens, los cultores Herculis Salarii, ${ }^{104}$ explicita la poderosa y antigua relación de Hércules con la sal (Fig. 7). El dios se erige, en Alba Fucens, en Roma y en toda Italia, como garante de la calidad y de la abundancia de la sal, básica para el ganado y los pastores de toda la península itálica. ${ }^{105}$

Pero además de Alba Fucens, son muchos otros los grandes santuarios dedicados a Hércules en la península itálica por los que pasaban los tratturi y los pastores con sus mercancías, entre ellas la sal. El colosal santuario de Hercules Victor en Tibur (Tivoli), situado en un lugar estratégico entre la llanura lacial y los Apeninos, estaba construido literalmente encima de un segmento de la Vía Tiburtina, con un túnel transitable que agilizaba los intercambios comerciales y el almacenamiento de reses y productos como la sal en el propio santuario. Praeneste (Palestrina), con su imponente y teatral santuario republicano de Fortuna Primigenia, ejemplifica perfectamente el aumento del nivel económico de la ciudad gracias a los intercambios comerciales y a los cultos que allí se veneraban, entre ellos también el de Hércules en el santuario extraurbano de Vigna Soleti. Y, por supuesto, la Campania también sobresalía en su veneración al dios itálico, aquí imbuido más tempranamente de los gustos helénicos. El culto de Hércules estaba presente en el santuario de Patturelli, en Capua, y, en general, en todo el golfo de Nápoles. Es justamente esta zona una parte del itinerario que sigue Hércules en su viaje desde Occidente hasta Grecia con la manada de bueyes de Gerión antes mencionados, pasando por el Foro Boario y también por el área flegrea de Campania. ${ }^{106}$ Justamente en relación con el dios, muy cerca de Pompeya surgía la dulcis Pompeia palus, vicina salinis Herculis, ${ }^{107}$ que vinculaba directamente

103. Cf. Torelli, 1993, pp. 113-114.

104. T(ito) Camerio T(iti) l(iberto) / Apto / cult(ores) Hercul(is) / Sala(rii). CIL IX $3961=$ EDCS 14804991.

105. Coarelli y La Regina, 1984, pp. 86-87; De Ruyt, 1982, pp. 122-126; De Visscher, 1962, pp. 15-69; s.v. 'Herakles', LIMC 4.1, pp. 772-777; Mertens, 1981, p. 42; Torelli, 1993, pp. 111-115.

106. Diod., IV 21-22.

107. Colum., R. r. X 135-136. 


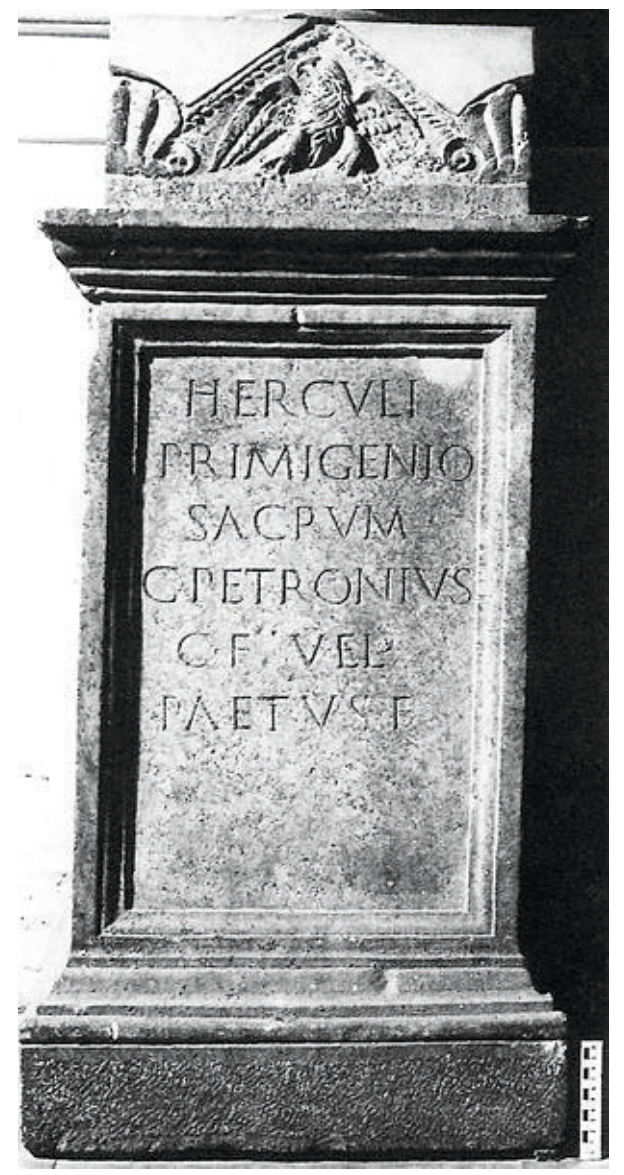

Fig. 7. Ara votiva del siglo I d.C dedicada a Hercules Primigenius (de EDCS 18600467)

al dios itálico con la sal, su explotación, su comercialización y su protección, como hemos visto para el resto de casos en Italia. ${ }^{108}$

\section{CONCLUSIONES}

Si realizásemos una panorámica de la situación del culto a Hércules en Italia durante el mundo arcaico pre y protourbano, veríamos una situación fragmentaria pero tremendamente sugestiva. El material se hallaba en las salinas dispersas por toda la 
costa itálica. Desde el Tirreno al Adriático, pasando por el mar Jonio, las salinas proveían a las poblaciones circundantes de un medio de subsistencia comercial básico tremendamente útil tanto para el consumo interno como para su intercambio en las zonas de interior. En un mundo tan ruralizado como el arcaico, los esfuerzos comerciales se centraban en el aprovechamiento de las manadas de bóvidos y los rebaños de ovejas, en el intercambio de cerámicas y pequeños manufactos, en la explotación de metales y, por supuesto, en el intercambio de la sal, complemento indispensable para la dieta del ganado. ${ }^{109}$ Hércules surge justamente en este contexto. Divinidad por antonomasia glotona, el Hércules itálico se convierte en el dios de referencia para los pastores, los comerciantes y demás profesionales relacionados con la sal. Hércules les protege y garantiza sus actividades comerciales. Es así como el dios, de alguna forma, se convierte en el compañero de viaje perfecto para el camino y los banquetes.

El surgimiento, desarrollo y auge de la trashumancia a finales de la República impulsa el desarrollo del culto de Hércules. Los tratturi y las vías dedicadas a la trashumancia y al trasporte de sal proliferan por toda Italia al igual que lo hacen los santuarios dedicados al dios. Dios, reses y comerciantes se compenetran los unos a los otros y así el comercio florece, mientras el dios vela por su fortuna. En Ostia es donde tiene lugar el mayor desarrollo de producción de sal, debido a las salinas cercanas. Es por ello que Roma, desde una fase muy temprana de su Historia, decide conquistar la zona, arrebatándosela a los etruscos, y establecer allí un presídium, el germen de Ostia Antica. Desde esta zona, la sal y los demás productos suben por el Tiber y los caminos de tierra hasta el primer gran emporio comercial: el Foro Boario. Debido a la importancia que posteriormente adquiere Roma y su topografía en la imaginación de los escritores antiguos griegos y latinos, en la Ciudad Eterna es donde más testimonios literarios quedan de este poso arcaizante ligado a la sal. Los mitos, como los de Acca Larentia, Caco o Evandro, dan fe de la presencia desde muy temprano de una divinidad protectora de los rebaños y la sal. Esta divinidad, Hércules, muy pronto se trasforma y adquiere nuevas características y leyendas provenientes del rico mundo imaginativo griego, pero la base permanece. Es, justamente, esta misma base la que

109. Hasta la aparición de los preparados para la alimentación animal, el aporte de sal debía realizarse de modo directo; así, hasta fechas relativamente recientes era frecuente ver una bola o bloque de sal en los pesebres, junto al forraje. Del mismo modo, algunas fiestas pastoriles incluyen, aún hoy en día, ritos como el de distribuir sal a los animales (Mangas Manjarrés y Hernando Sobrino, 2011, p. 14). Los aportes diarios necesarios para cada tipo de res varían en función de su peso y necesidades nutricionales, desde los 55 gr./día de media del ganado vacuno hasta los 5 gr./día del ganado caprino, según las estimaciones de Mangas Manjarrés y Hernando Sobrino, 1991, pp. 220-221. 
se populariza a partir del siglo II a.C. y la que los autores apenas llegan a vislumbrar entre la complejidad de los ritos. El emperador Cómodo, conocedor del potencial del dios aún en su época, no cesa de protegerle e imitarle, ya fuera en la arena o a través de la protección de su culto en el Ara Máxima.

De forma análoga sucede en el mundo del interior apenínico. Tivoli, Praeneste, al zona samnita o Alba Fucens, por poner los ejemplos más célebres, se vuelcan con la adecuación y veneración de su culto. Proliferan desde el siglo II a.C. los santuarios del dios por todas partes, signo de que la popularidad y conservación de los atributos tradicionales del dios siguen vigentes, generación tras generación. El Hércules itálico tranquiliza, protege y a la vez es un dios conocido y fuerte, del que se puede uno fiar y del que no se desconfía por ser extranjero, pese a lo que pueda parecer a través de su imagen. Y es que el mundo tardorrepublicano es ya un mundo muy acostumbrado a la imagen griega y es por ello que las leyendas se entremezclan y las imágenes se adecuan a unas cualidades que, por supuesto, ni siquiera Lisipo habría pensado en ellas en ámbito griego.

Sigue siendo necesario, por tanto, hoy en día seguir profundizando en cómo la sal cambia la manera de pensar de los romanos. Hércules y otras divinidades son fruto del razonamiento y anhelos de generaciones de itálicos deseosos de estabilidad y prosperidad comercial. Los dioses surgen en este contexto para garantizar todo ello y velar por la prosperidad de su gente. Al igual que hace la sal, regalo del mar y la tierra para disfrute de reses y hombres, perfecta para conservar los alimentos durante los banquetes y para preparar salsas con ella. En definitiva, el elemento básico que toda población necesita para su correcto funcionamiento, tanto biológico y comercial, como religioso e intelectual. 


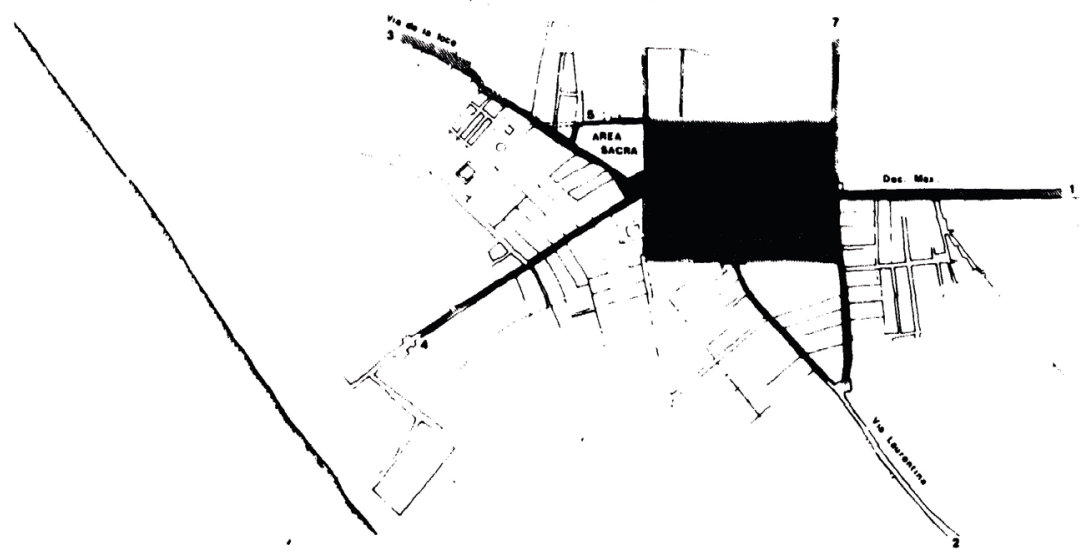

Fig. 8. Planta de Ostia antes de la construcción de la muralla silana (de Mar, 1990, p. 144)

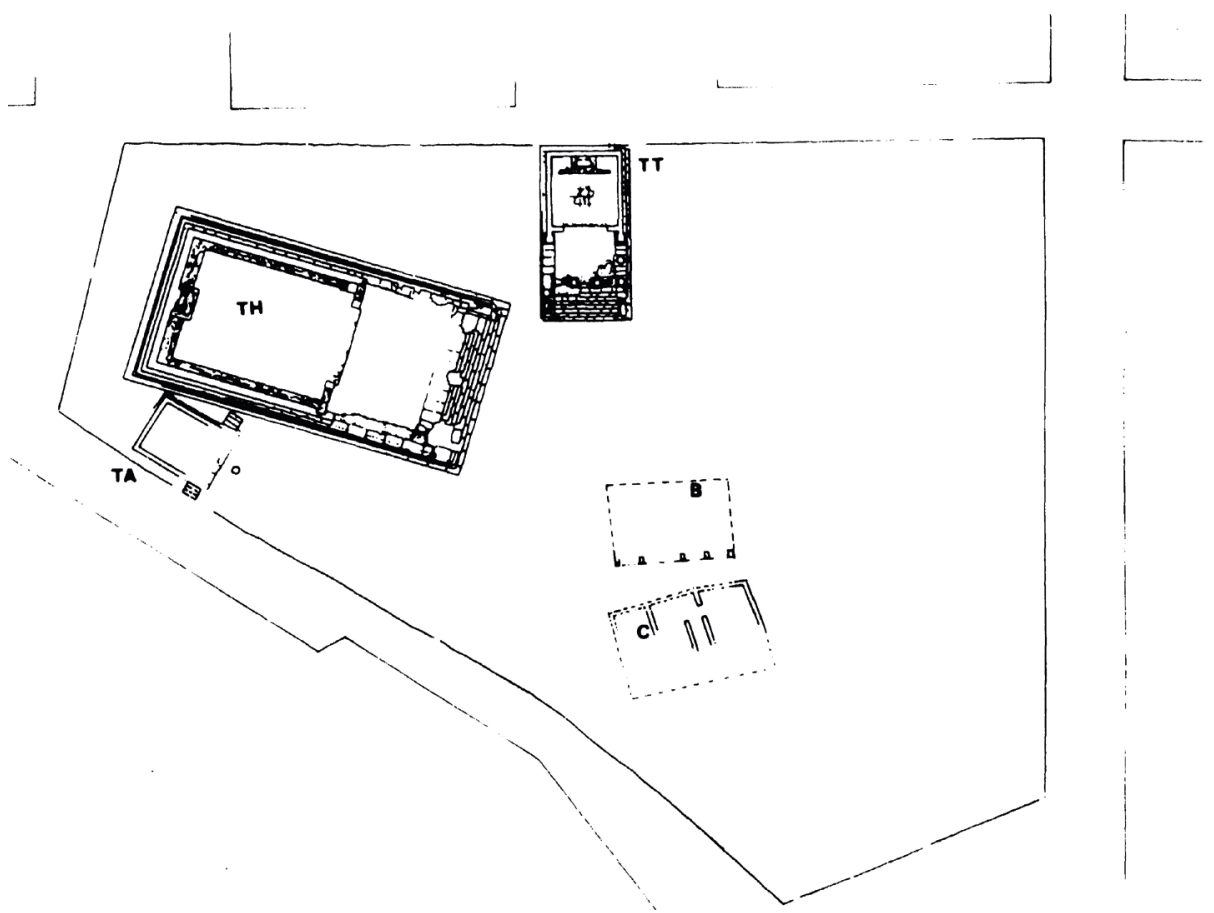

Fig. 9. Los primeros elementos conocidos en el santuario de Hércules en Osta Antica (ss. II y I a.C.): Templo Tetrástilo (TT), Templo de Hércules (TH), Templo del Ara Redonda (TA) y edificios anexos (B y C). E: 1/750 aprox. (de Mar, 1990, p. 147) 


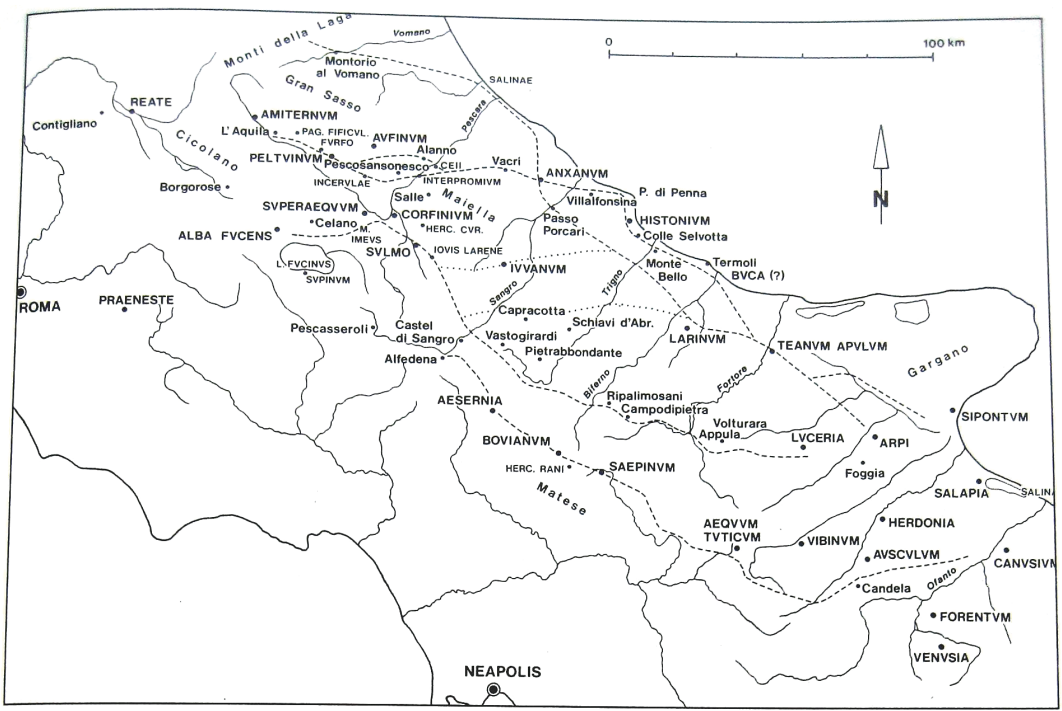

Fig. 10. Principales tratturi entre Apulia y la Sabina (de Van Wonterghem, 1999, p. 415)

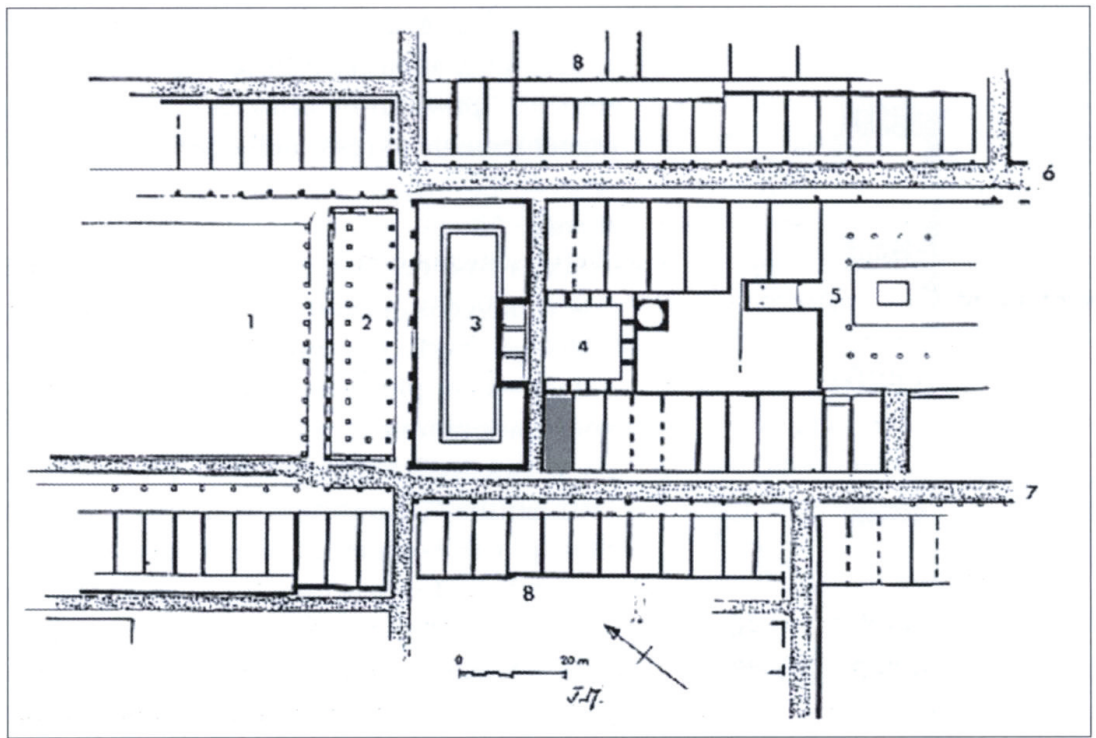

Fig. 11. Plano urbano del centro de Alba Fucens tras la intervención tardorrepublicana (de Liberatore, 2004, p. 124) 


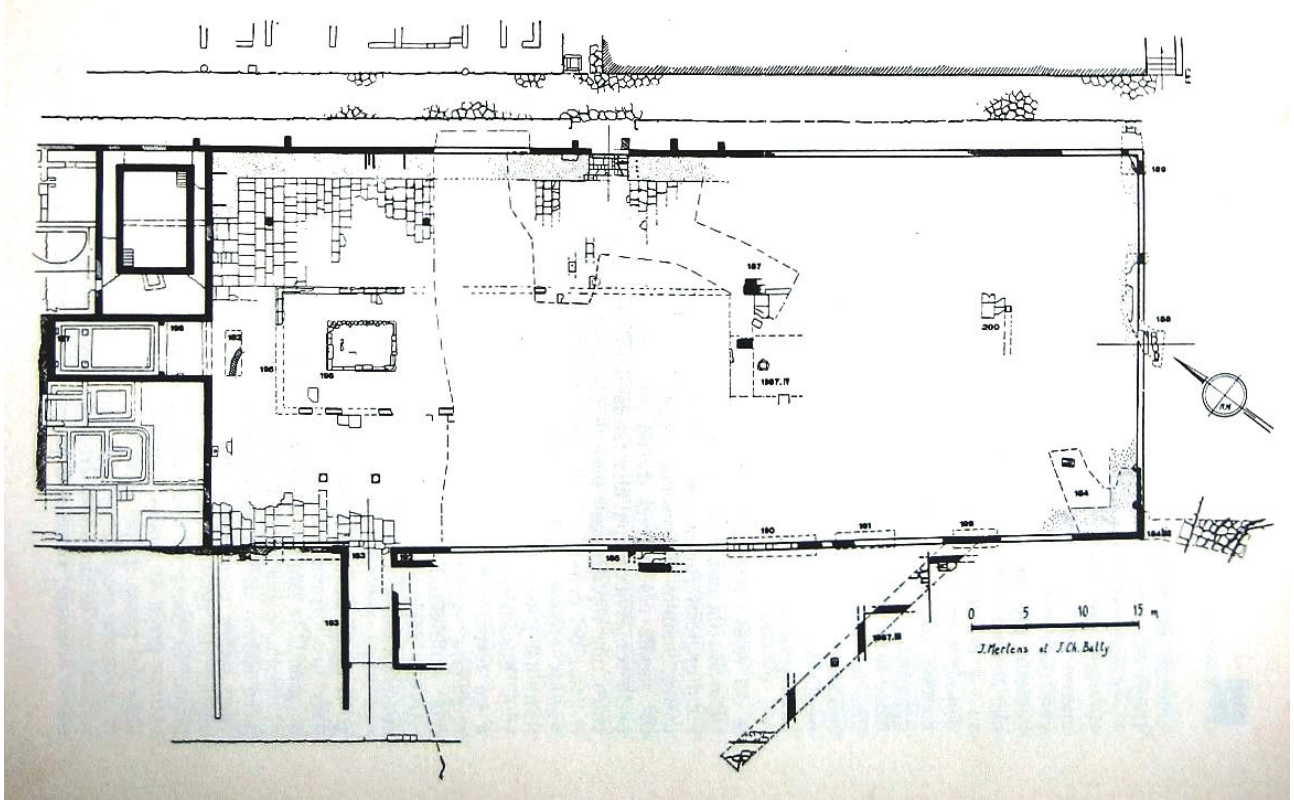

Fig. 12. Santuario de Hercules Salarius en Alba Fucens (de Coarelli y La Regina, 1984, p. 85)
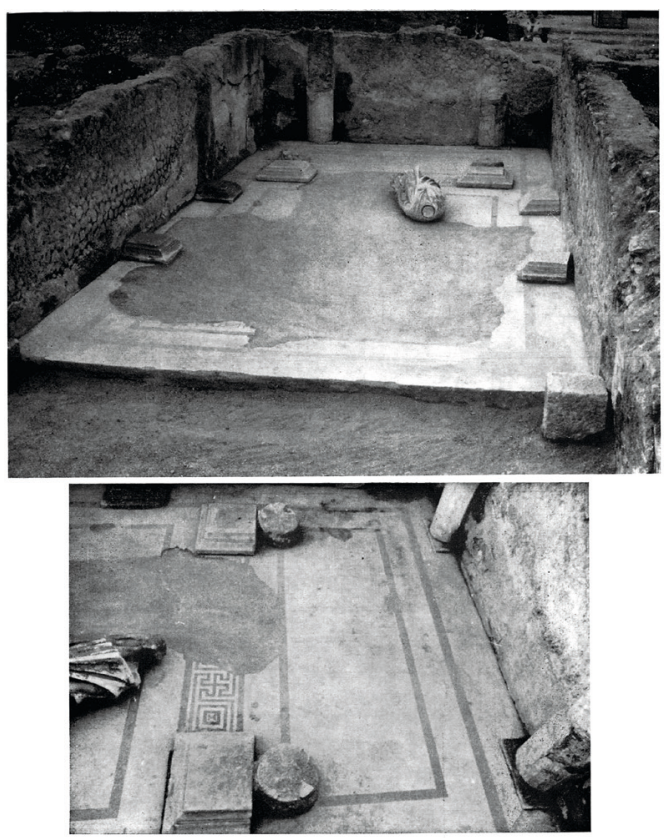

Fig. 13. Sacellum de Hercules Salarius en Alba Fucens (arriba) y detalle de los restos de la edícula o ciborium (abajo) (de De Visscher, 1962, p. 13) 


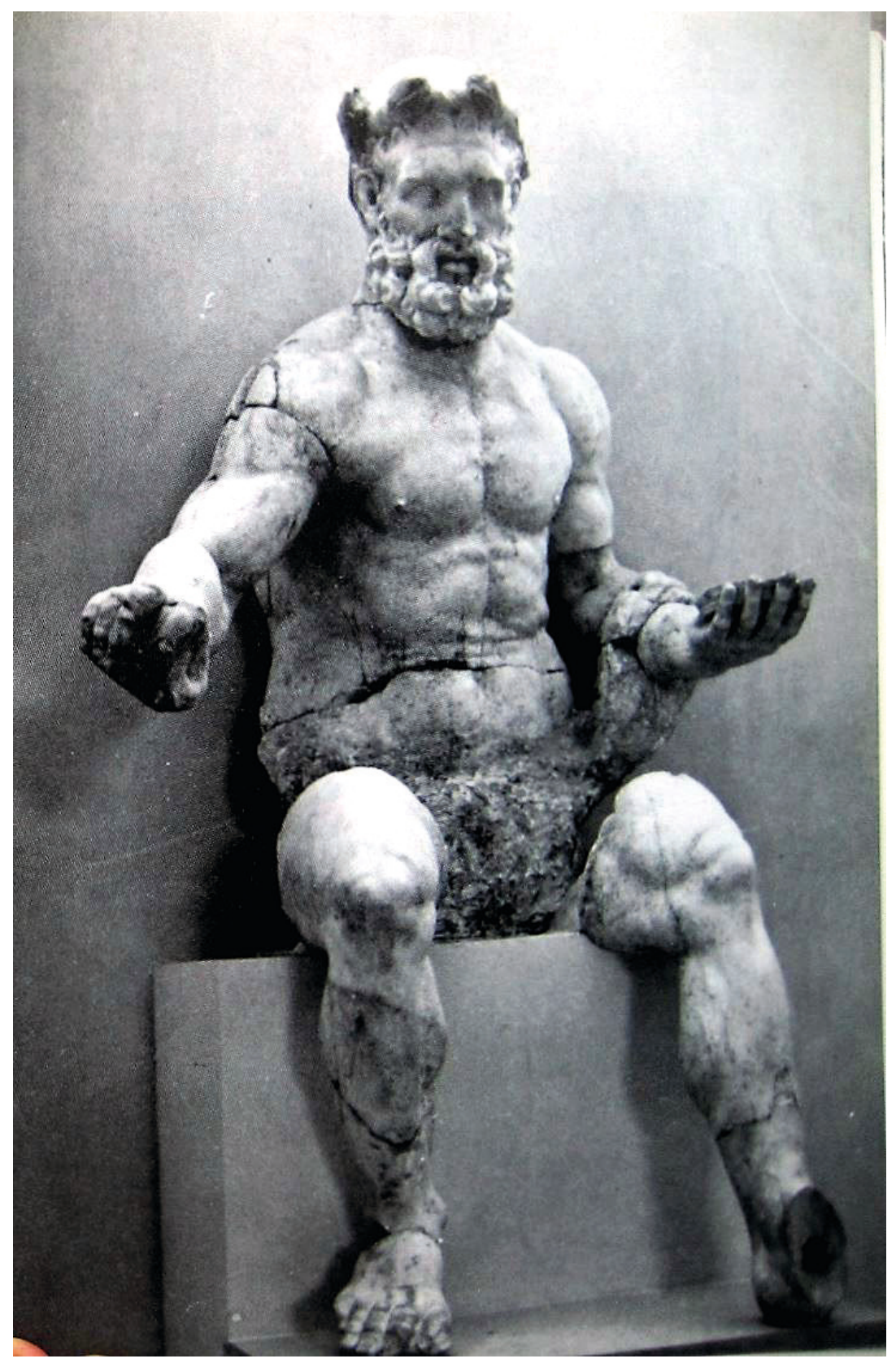

Fig. 14. Hércules Epitrapezios. Museo Nazionale di Chieti (de Mertens, 1981, p. 43) 


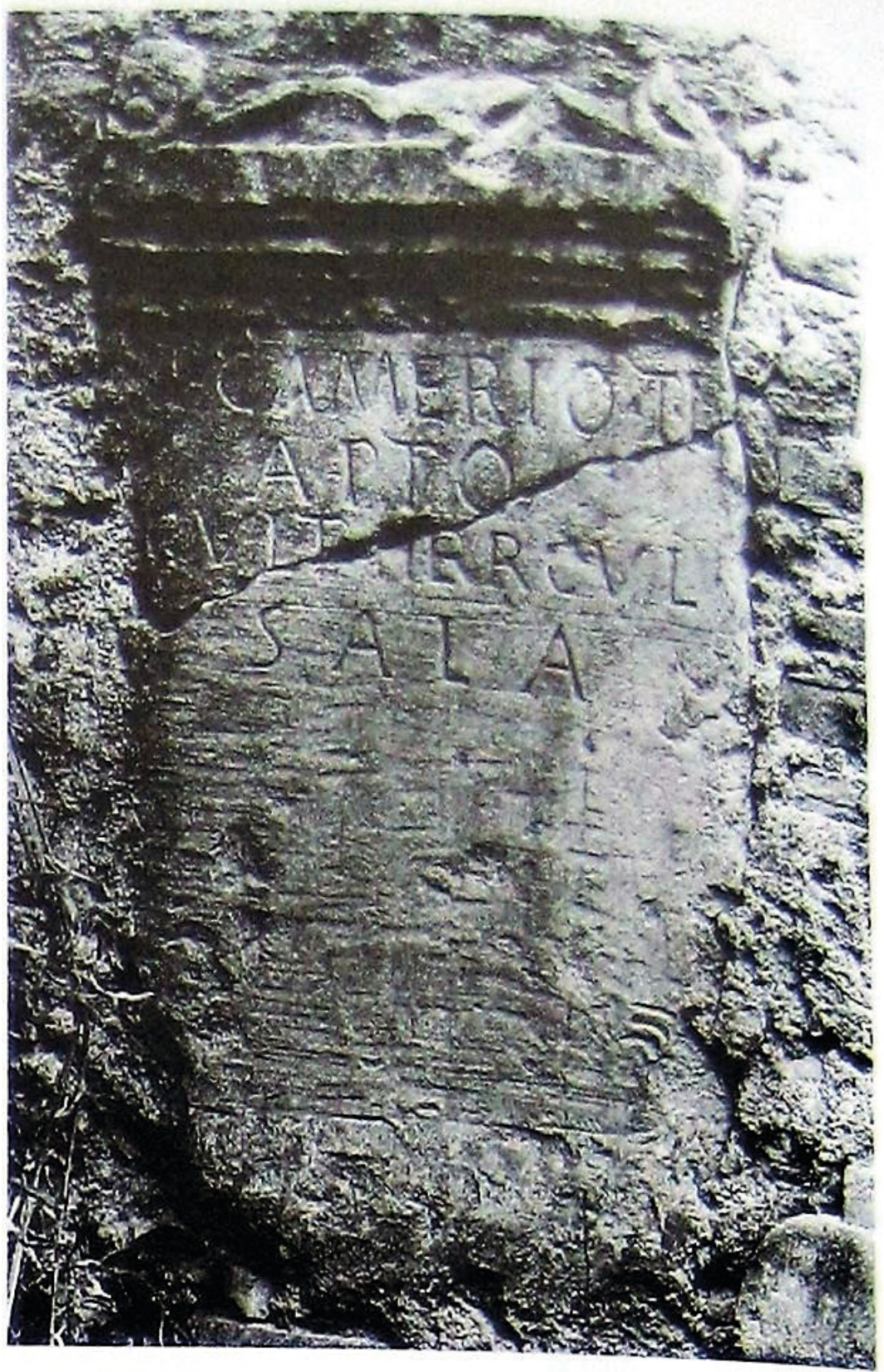

Fig. 15. Ara erigida en honor del liberto Tito Camerio Apto (de Van Wonterghem, 1999, p. 426) 


\section{Bibliografía}

Acconcia, V. y Rizzitelli, C. (eds.) (2008). Materiali per Populonia. 7. Pisa: Edizioni ETS.

Alexianu, M., Curcă, R.-G. y Weller, O. (2011). Archaeology and anthropology of salt: a diachronic approach: proceedings of the international colloquium, 1-5 October 2008, Al. I. Cuza University (Iași, Romania). Oxford: Archaeopress.

Alvino, G. (2003). Via Salaria. Roma: Istituto poligrafico e Zecca dello Stato, Libreria dello Stato.

ARA = Carandini, A. y Carafa, P. (eds.) (2013). Atlante di Roma antica. Biografia e ritratti della città. Milano: Electa.

Attilio Levi, M., 1997. Ercole e Roma. Roma.

Baldassarre, I., Bragantini, I. y Morselli, C. (1996). Necropoli di Porto. Isola sacra. Roma: Istituto poligrafico e Zecca dello Stato, Libreria dello Stato.

Balty, J.C. (1964). A propos de quelques séries de brozes italiques et du culte d'Hercule en Italie centrale. Problèmes de orientations de recherches. Alumni, 34, pp. 45-54.

Battaglini, G. (2005). La sal en los orígenes de la ciudad de Roma. En Frías Castillejo, 2005, pp. 65-75.

Battaglini, G. (2016). Su alcuni aspetti relativi ad Ercole e il sale nelle origini di Roma. En Gasparini, 2016, pp. 51-64.

Becatti, G. (1939). Il culto di Ercole ad Ostia ed un nuovo rilievo votivo. Bullettino della Commissione Archeologica del Governatorato di Roma, 67, pp. 37-60.

Broughton, T.R.S. (1952). The Magistrates of the Roman Republic. New York: American Philological Association.

Bruun, C. y Zevi, A.G. (eds.) (2002). Ostia e Portus nelle loro relazioni con Roma: atti del Convegno all'Institutum Romanum Finlandiae, 3 e 4 dicembre 1999. Roma: Istitutum Romanum Finlandiae.

Capini, S. y Di Niro, A. (eds.) (1991). Samnium. Archeologia del Molise. Catalogo della Mostra. Roma: Quasar.

Carandini, A. (1997). La nascita di Roma. Dèi, lari, eroi e uomini all'alba di una civiltà. Torino: G. Einaudi.

Caravaggi, L. y Morelli, C. (2014). Paesaggi dell'archeologia invisibile: il caso del distretto Portuense. Macerata: Quodlibet.

Carusi, C. (2007). Le commerce du sel dans l'Antiquité grecque (VIe siècle av. J.-C. - IIe siècle apr. J.-C.). En Monah, Weller y Dumitroaia, 2007, pp. 221-233.

Carusi, C. (2008). Intorno alla produzione di sale a Populonia e nell'ager cosanus: due casi di studio a confronto. En Acconcia y Rizzitelli, 2008, pp. 303-312.

Carusi, C. (2009). Il sale nel mondo greco (VI a.C. - III d.C.): luoghi di produzione, circolazione commerciale, regimi di sfruttamento nel contesto del Mediterraneo antico. Bari: Edipuglia.

Carusi, C. (2011). Hypotheses, considerations - and unknown factors - regarding the demand for salt in ancient Greece. En Alexianu, Curcă y Weller, 2011, pp. 149-154. 
Castagnoli, F. (1979). Il culto della Mater Matuta e della Fortuna nel Foro Boario. StRom, 27, pp. 145-152.

Cazzella, A. (2001). Sviluppi verso l'urbanizzazione a Roma alla luce dei recenti scavi nel Giardino Romano. Bullettino della Commissione Archeologica Comunale di Roma, 102, pp. 265-268.

Cébeillac-Gervasoni, M. (2013). Lo scavo e le iscrizioni della tomba J dell' Isola Sacra. Mélanges de l'École Française de Rome, 126, pp. 241-249.

Cébeillac-Gervasoni, M., Caldelli, M.L. y Zevi, F. (2010). Epigrafia latina: Ostia: cento iscrizioni in contesto. Roma: Quasar.

Cebeillac-Gervasoni, M. y Morelli, C. (2014). Les conductores du Campus Salinarum Romanarum. Mélanges de l'Ecole française de Rome. Moyen Âge, 126.1, pp. 23-33.

Cid López, R.M. y García Fernández, E.B. (eds.) (2013). Debita verba. Estudios en homenaje al profesor Julio Mangas Manjarrés. Oviedo: Servicio de Publicaciones de la Universidad de Oviedo.

Coarelli, F. (1981). Dintorni di Roma. Roma y Bari: G. Laterza.

Coarelli, F. (1988). Il Foro Boario dalle origini alla fine della Repubblica. Roma: Quasar.

Coarelli, F. y La Regina, A. (1984). Abruzzo, Molise. Roma y Bari: Laterza.

Cristofani, M. y Zevi, F. (eds.) (1995). Studi sulla Campania preromana. Roma: Bretschneider Giorgio.

DA = Daremberg, C.V. y Saglio, E. (1877-1919). Dictionnaire des Antiquités grecques et romaines. Paris.

De Ruyt, F. (1982). Alba Fucens. Sculptures d'Alba Fucens (pierre, marbre, bronze). Catalogue raisonné. Roma: Centre Belge de Recherches Archéologiques en Italie Centrale et Méridionale.

De Visscher, F. (1962). Heracles Epitrapezios. Paris: Boccard.

DGRBM = Smith, W. (ed.) (1844-1870). Dictionary of Greek and Roman Biography and Mythology. London y Boston: Little, Brown and co..

Di Felice, P. y Torrieri, V. (2006). Museo Civico Archeologico F. Savini Teramo. Teramo: Emmegrafica.

EAA = Becatti, G. (ed.) (1958-1984). Enciclopedia dell'Arte Antica, Classica e Orientale. Roma: Istituto della Enciclopedia italiana.

Faustoferri, A. y Lock, G. (2008). Archaeology and landscape in central Italy: Papers im memory of John A. Lloyd. Oxford: School of Archaeology.

Fea, C. (1831). Storia delle saline di Ostia introdotte da Anco Marcio quarto re di Roma dopo la fondazione di quella città. Roma: Stamperia della Rev. Camera Apostólica.

Ferenczy, E. (1976). From the Patrician State to the Patricio-Plebeian State. Budapest: Akadémia Kiadó.

Filippi, D. (2005). Il Velabro e le origini del Foro. Workshop di archeologia classica, 2, pp. 93 115.

Frías Castillejo, C. et al. (eds.) (2005). III Congreso de estudios históricos. El Mediterráneo: la cultura del mar y la sal. Santa Pola: Ayuntamiento de Santa Pola. 
Fugazzola Delpino, M.A. (1976). Testimonianze di cultura appenninica nel Lazio. Firenze: Sansoni.

García Sánchez, J., Mañas Romero, I. y Salcedo, F. (eds.) (2015). Navigare necesse est. Estudios en homenaje a José María Luzón Nogué. Madrid: Universidad Complutense Madrid.

Gasparini, V. (ed.) (2016). Vestigia: miscellanea di studi storico-religiosi in onore di Filippo Coarelli nel suo $80^{\circ}$ anniversario. Stuttgart: Franz Steiner Verlag.

Giovannini, A. (1985). Le Sel et la fortune de Rome. Athenaeum, 63, pp. 373-387.

Hernando Sobrino, M.d.R. (2014). Hércules en la Meseta. Testimonios, carácter y conexiones. En Mangas Manjarrés y Novillo López, 2014, pp. 383-411.

Keay, S.J. y Paroli, L. (2011). Portus and its hinterland: recent archaeological research. London: British School at Rome.

La Regina, A. (1976). Il Sannio. En Zanker, 1976, pp. 219-254.

Lanciani, R. (1888). Il Campus Salinarum Romanarum. Bullettino della Commissione Archeologica Comunale di Roma, 16, pp. 83-91.

Le Bonniec, H. (1958). Le culte de Cérès à Rome des origines à la fin de la République. Paris: C. Klincksieck.

Liberatore, D. (2004). Alba Fucens. Studi di storia e di topografia. Bari: Edipuglia.

LIMC = VV.AA. (1981-1999). Lexicon Iconographicum Mythologiae Classicae. Düsseldorf: Artemis.

LTUR = Steinby, E.M. (ed.) (1993-2000). Lexicon topographicum urbis Romae. Roma: Quasar. LTURS = La Regina, A. (ed.) (2001-2008). Lexicon Topographicum Urbis Romae. Suburbium. Roma: Quasar.

Lugli, G. (1985). Studi minori di topografia antica. Roma: De Luca.

Lyngby, H. (1954). Beiträge zur Topographie des Forum-Boarium-Gebietes in Rom: Testimonien nebst Kommentar und kritischem Apparat. Lund: C.W.K. Gleerup.

Mangas Manjarrés, J. y Hernando Sobrino, M.d.R. (1991). La sal y las relaciones intercomunitarias en la Península Ibérica durante la Antigüedad. Memorias de Historia Antigua, 11-12, pp. 219-332.

Mangas Manjarrés, J. y Hernando Sobrino, M.d.R. (2011). La sal en la Hispania romana. Madrid: Arcos Libros - La Muralla S.L.

Mangas Manjarrés, J. y Novillo López, M.Á. (eds.) (2014). Santuarios suburbanos y del territorio en las ciudades romanas. Madrid: Instituto Ciencias Antigüedad.

Mar, R. (1990). El Santuario de Hércules y la urbanística de Ostia. Archivo Español de Arqueología, 63.161, pp. 137-160.

Marcos Casquero, M.A. (2002). El exótico culto a Hércules en el Ara Máxima. Revista de estudios latinos (RELat), 2, pp. 65-106.

Martin, H.G. (1987). Römische Tempelkultbilder: eine archäologische Untersuchung zur späten Republik. Roma: "L'Erma” di Bretschneider.

Mastrocinque, A. (ed.) (1993). Ercole in Occidente. Atti del colloquio internazionale, Trento 7 marzo 1990. Trento: Dipartimento di scienze filologiche e storiche. 
Mertens, J. (1981). Alba Fucens. Bruselas: Centre belge de recherches archeologiques en Italie centrale et meridionale.

Moinier, B. y Weller, O. (2015). Le sel dans l'Antiquité: ou les cristaux d'Aphrodite. Paris: Les Belles Lettres.

Monah, D., Weller, O. y Dumitroaia, G. (2007). L'exploitation du sel a travers le temps. PiatraNeamt: Constantin Matasu.

Morelli, C. (2011). Il porto di Claudio: nuove scoperte. En Keay y Paroli, 2011, pp. 47-65.

Morelli, C. (2014). L'ager portuensis, la dimensione territoriale dei contesti archeologici. En Caravaggi y Morelli, 2014, pp. 52-71.

Morelli, C. y Forte, V. (2014). Il Campus Salinarum Romanarum e l'epigrafe dei conductores. Mélanges de l'Ecole française de Rome. Antiquité, 126.1, pp, 9-21.

Morelli, C., Forte, V. y Carbonara, A. (2008). The landscape of the Ager Portuensis, Rome: some new discoveries, 2000-2002. En Faustoferri y Lock, 2008, pp. 213-232.

Murolo, N. (1995). Le saline herculeae di Pompei. Produzione del sale e culto di Ercole nella Campania antica. En Cristofani y Zevi, 1995, pp. 105-123.

Musti, D. (ed.) (2014). Fare storia antica: in ricordo di Domenico Musti (Roma, 18-19 aprile 2012). Roma: Accademia Naz. Del Lincei.

Olcese, G. (2017a). Ceramiche da contesti repubblicani del territorio di Ostia. Roma: Quasar.

Olcese, G. (2017b). Le anfore del contesto della ruota idraulica di Ostia Antica: archeologia e archeometria. Archeologia Classica, 68, pp. 197-224.

Olcese, G. y Zevi, F. (2004). Scoperte recenti nelle saline portuensi (Campus salinarum romanarum) e un progetto di ricerca sulla ceramica di area ostiense in età repubblicana. En Zevi y Turchetti, 2004, pp. 43-55.

Palmer, R.E.A. (1965). The Censors of 312 B.C. and the State Religion. Historia, 14, pp. 293 324.

Palmer, R.E.A. (1990). Cults of Hercules, Apollo Caelispex and Fortuna in and Around the Roman Cattle Market. JRA , 3, pp. 234-244.

Pavolini, C. (2006). Ostia. Roma y Bari: Laterza.

Petrocelli, E. (ed.) (1999). Civiltà della transumanza. Storia, cultura e valorizzazione dei tratturi e del mondo pastorale in Abruzzo, Molise, Puglia, Campania e Basilicata. Isernia: C. Iannone.

Plácido Suárez, D. (1993). Le vie di Ercole nell'estremo Occidente. En Mastrocinque, 1993, pp. 63-80.

Plácido Suárez, D. (2005). Los viajes de los héroes, los riesgos del mar y los usos de la sal en el extremo occidente. En Frías Castillejo, 2005, pp. 57-63.

Plácido Suárez, D. (2013). Entre Oriente y Occidente: las fundaciones coloniales y los viajes de los héroes. En Cid López y García Fernández, 2013, pp. 525-541.

Prosdocimi, A.L. (1978). Popoli e civiltà dell' Italia antica. Vol. 6\1: Lingue e dialetti nell' Italia antica. Roma: Spazio Tre.

Richardson, L. (1992). A New Topographical Dictionary of Ancient Rome. Baltimore: Johns Hopkins University Press. 
Ruggiero, I. (1987). Il tempio di Portuno nel Foro Boario. BollUnStArte, 80, pp. 16-22.

Ruggiero, I. (1991-1992). Ricerche sul tempio di Portuno nel Foro Boario: per una rilettura del monumento. BCom, 94, pp. 253-286.

Russo, S. y Goffredo, R. (eds.) (2018). Saline e sale nell'antichità: atti del III convegno sul Basso Tavoliere. Bari: Edipuglia.

Scopacasa, R. (2015). Ancient Samnium: Settlement, Culture, and Identity between History and Archaeology. Oxford: Oxford University Press.

Sordi, M. (ed.) (1984). I santuari e la guerra nel mondo classico. Milano: Vita e Pensiero.

Sordi, M. (1984). Il Santuario di Cerere, Libero e Libera e il tribunato della plebe. En Sordi, 1984, pp. 127-139.

$S R=$ Momigliano, A. y Schiavone, A. (eds.) (1988-1993). Storia di Roma. Torino: Einaudi.

Stek, T.D. (2009). Cult places and cultural change in Republican Italy. A contextual approach to religious aspects of rural society after the Roman conquest. Amsterdam: Amsterdam University Press.

Torelli, M. (1993). Gli aromi e il sale: Afrodite ed Eracle nell' Emporia arcaica dell' Italia. En Mastrocinque, 1993, pp. 91-117.

Torelli, M. (2006). Ara Maxima Herculis: storia di un monumento. Mélanges de l'Ecole française de Rome. Antiquité, 118.2, pp. 573-620.

Torelli, M. (2015). Il tempio di Ercole, la c.d. schola sul decumano e i Plautii Hateriani di Leptis Magna. En García Sánchez, Mañas Romero y Salcedo, 2015, pp. 257-270.

Van Berchem, D. (1967). Sanctuaires d'Hercule-Melqart (Suite et fin): III. Rome. Syria, 44.34, pp. 307-338.

Van Wonterghem, F. (1999). Il culto di Ercole e la pastorizia nell' Italia centrale. En Petrocelli, 1999, pp. 413-428.

Zanker, P. (ed.) (1976). Hellenismus in Mittelitalien: Kolloquium in Goettingen vom 5. bis 9. Juni 1974. Goettingen: Vandenhoeck und Ruprecht.

Zevi, A.G. y Turchetti, R. (eds.) (2004). Méditerranée occidentale antique: les échanges. Soveria Mannelli: Rubbettino.

Zevi, F. (2002a). Appunti per una storia di Ostia repubblicana. Mélanges de l'École Française de Rome, 114.1, pp. 13-58.

Zevi, F. (2002b). Origini di Ostia. En Bruun y Zevi, 2002, pp. 11-32.

Zevi, F. (2012). Culti ed edifici templari di Ostia repubblicana. Ostraka, Rivista di antichità, Vol. spec. 2012, pp. 537-563.

Zevi, F. (2014). L'archeologia di Roma arcaica nella visione di uno storico En Musti, 2014, pp. 191-207.

Ziolkowski, A. (1988). Mummius' Temple of Hercules Victor and the Round Temple on the Tiber. Phoenix, 42, pp. 309-333.

Ziolkowski, A. (1992). The Temples of Mid-republican Rome and their Historical and Topographical context. Roma: L'Erma di Bretschneider. 